\title{
DIRECT ENERGY CONVERSION STUDIES WITH EMPHASIS ON THOSE INVOLVING NUCLEAR RADIATION
}

\author{
G. H. Miley \\ University of Illinois
}

The direct energy conversion activities at the University of Illınois are scattered throughout the following four departments that have related activities Nuclear Engineering, Electrical Engineerıng, Mechanical Engineerıng and Aeronautical Engineering. In 1966 a committee was formed to answer the question of whether or not direct energy conversion should be organızed as a separate interdisciplinary field, much the same as nuclear engineering. After looking at this question, the committee decided it should not be, but that an informal association and close communication should continue between the activities in the various departments.

There are three main courses at Illinois that deal with direct energy conversion. One titled Direct Energy Conversion is taught at the senior or first-year graduate level in mechanıcal engineerıng. A generalızed magnetohydrodynamics (MHD) course is offered in aeronautical engineering, and there is a graduate level special topics course in nuclear engineering. Both the direct energy conversion and the special topics courses have a modest number of laboratory experiments which were described at an earlier ANS meetıng. ${ }^{1}$

A basic problem in direct energy conversion, from an educator's point of view, is that it is as complex, as interdisciplinary, as is nuclear engineering itself. Someone who is interested in specializing in this field at the graduate level must consider a multitude of possible courses. Usually it boils down to a question of whether or not one wants to concentrate in solid state areas or in plasma areas.

At the national level the American Society tor Engineering Education has formed a committee to study the educational aspects of energy conversion. Several sessions at the 1968 ASEE annual meeting in Los Angeles will grapple with the problem of "objective criteria" in energy conversion education and also with detalled course structure. Also, the ASEE committee is currently trying to inaugurate a summer practice school for graduate students at one of the NASA laboratories. It would be similar to the current Argonne practice school except it would be for students interested in energy conversion. Another external activity that is rather unique is the organization of the energy conversion activities at the University of Pennsylvania into an interdisciplinary laboratory called the Direct Conversion Institute under the sponsorship of NASA. ${ }^{2}$ 


\section{DISCLAIMER}

This report was prepared as an account of work sponsored by an agency of the United States Government. Neither the United States Government nor any agency Thereof, nor any of their employees, makes any warranty, express or implied, or assumes any legal liability or responsibility for the accuracy, completeness, or usefulness of any information, apparatus, product, or process disclosed, or represents that its use would not infringe privately owned rights. Reference herein to any specific commercial product, process, or service by trade name, trademark, manufacturer, or otherwise does not necessarily constitute or imply its endorsement, recommendation, or favoring by the United States Government or any agency thereof. The views and opinions of authors expressed herein do not necessarily state or reflect those of the United States Government or any agency thereof. 


\section{DISCLAIMER}

Portions of this document may be illegible in electronic image products. Images are produced from the best available original document. 
Consider how direct energy conversion is related to nuclear eng neerıng. One might ask why should nuclear engineers become involved in this? There is a motivation from a standpoint of converting energy from the reactor or a radioisotope power source into a convenient energy form, e.g. , electrical energy. From the educator's point of view, one has to worry how this fits into the educational program. This involves identifying the fundamental principles that underlie the "Big Four," thermionics, MHD, fuel cells and photovoltaic cells. On the surface these may seem to be similar, but the basic mechanisms are quite different. One has to worry, particularly at a graduate level, about how to present this material in depth without ending up with a survey course. This is particularly important if one wishes to superimpose subject matter of this type on another broad area such as nuclear engineering which is itself an interdisciplinary study. (The details of nuclear engineering at Illınois were discussed at an earlier Gatlınburg meetıng. ${ }^{3}$ )

The problem of the proper place for direct energy conversion in the Nuclear Engineering Department was one which was faced several years ago when considerıng a research and teaching program involving nuclear radiation. 4 The reasoning was as follows

The existing background of nuclear engineering students could be used as a base without adding additional fundamental courses. Thus, one could launch into a fairly high level graduate course in an area which represents an obligation for a nuclear engineer. The subject matter is such that only persons interested in nuclear engineering are likely to grapple with it. In contrast, other areas in direct conversion, such as thermionics, which involve a heat cycle draw people from a wide range of disciplines, because they have much broader applications.

Several other thoughts in the selection and definition of this work should be noted. The final form of energy in these studies has never been restricted. Electrical energy is not necessarily the ultimate goal. Instrumentation is not ruled out because ending up with power for some high-power operation is interesting. The differences between instrumentation and power concepts are not that great. The major difference lies in the objectives.

Looking back to thermionics, there is a 1957 article in one of the IEEE journals that said that thermionics would never be practical because of an inherently low efficiency. The author apparently based this conclusion on the then state of the art of electron tube technology. It was clear within a year that he was wrong. There is a subtle distinction, and it is often difficult to predict when conditions will be "ripe" so that instrumentation concepts can pass over into power concepts.

I. Research Involving Nuclear Radiation

The influence of the above philosophy will become apparent in the description of some of the activities in the area of energy conversion involving nuclear radiation. 


\section{TABLE I}

Direct Energy Conversion Involving Nuclear Radiation

1. Direct Collection of Charged Particles

$\begin{array}{ll}\text { Examples } & \text { Gamma Radiation }- \text { Y E.C. } \\ & \text { (Compton or Photoelectrons) } \\ & \text { Alpha Particles }-\alpha-\text { Cell } \\ & \text { Beta Particles }-\mathrm{Kr}-85 \text { Battery }\end{array}$

2. Radiation Induced Ionization and Excitation

a. Direct Conversion

Examples - Ionization Electric Cell, Chemonuclear, Lase $r$

b. Space Charge Neutralization in Thermionics

c. Nonthermal Ionization in $\mathrm{MHD}$

As outlined in Table I, two major areas are involved. One has to do with direct collection of charged particles, and the other has to do with radiation-induced ionization and excitation. One way to convert nuclear radiation energy might be to erect a large potential barrier in its path, and direct collection effectively does just that. As an example, visualize a vacuum capacitor with one plate coated with a charged particle emitter. These particles go to the other plate and charge it, building up an electrical potential. Additional particles leaving the emitting plate are forced to overcome this potential, thus converting their kinetic energy to potential energy. This is a brute-force method, but it is simple.

One might ask whether or not the same thing could be accomplished using a number of smaller barriers. This is in effect what happens in the ionization and excitation route. Essentially atomic level potenilals represent, instead of one monstrous potential barrier, a number of smaller barriers which convert the radiation energy to potential energy or other forms of energy. The problem here is that each step typically curns out to be inefficient. The result is once the energy has passed from its original form to ionizationexcitation, it has already been randomized, thus it ends up in several forms. If one is trying to build a cycle which operates on a single form, e.g., potential energy, the others are lost.

Examples of these concepts are also listed in Table I. Direct collection devices can be classified according to the source used, e.g., radioactive sources such as alpha or beta particle emitters, fission fragments from nuclear fission or Compton electrons from gamma interactions. Consider radiation induced ionization. One could actually convert radiation energy to electrical energy by producing ionization and then separating the ion pairs, 1.e., ions and electrons. For example, consider the irradiation of a gas confined between two plates. This sounds like an ionization chamber. However, the ion chamber uses a voltage difference imposed by a battery or other external power supply to separate the ion pairs. It can easily be shown that 
this does not produce a useful power output. What is needed is an intrinsic driving force to separate the ion pairs. One straight-forward way to do this is to use plates constructed of different materials, i.e., use the difference in work functions between the two plates to produce the voltage difference. This has been done, and Ohmart Corporatıon makes such devices commercially as part of a gamma gauge. ${ }^{5}$ Using the Illınoıs TRIGA as a radiation source, a similar device has been studied. 6 The following is a quick mental calculation of the efficiency which might be obtained. Consider work function differences of the order of 1 or 2 volts. It takes approximately $30 \mathrm{eV}$ to form an ion pair. Thus if one were able to collect all of the ion pairs produced, an ideal efficiency of (1-2)/30 or $\sim 6$ per cent might be obtained. This 1s, of course, an upper limit. Efficiencies have dropped in this multistep barrier concept. Still the concept may be valuable in special situations.

There are other ways of providing the driving force to separate the ions, for example, two plates made of the same material but held at different temperatures with a plasma between them. Because of the difference in temperature, the plasma potential relative to each plate will be different, and one can use this potential difference to extract electrical energy. Some experiments of this type have measured unexpectedly large potential differences, and this is known as the "Klein Effect." 7

If electrical energy is not wanted, there are other possibilities. Ionizing radiation can be used to promote chemical reactions in order to derive chemical energy. This has led to the chemonuclear reactor concept under study at Brookhaven National Laboratory and elsewhere. 8 One could pump a laser with nuclear radiation and obtain optical or infrared radiation. This would amount to changing the radiation wave length or frequency. 9 Instead of ionization this approach depends upon excitation of the medium.

Other categories which involve radiation have to do with using it more or less as a catalyst. In thermionic devices one could use radiation to produce ionization, i.e., a plasma in the region between the plates and hopefully neutralize the space charge which is one of the fundamental problems in a thermionic diode. This concept has been examined in some detall by Jamerson et al. at General Motors. 10 The same type of thing could be considered in MHD to produce nonequilibrium ionization. 11 This would in concept lead to a reasonable conductivity without seeding or high temperatures.

A. Fission-Electric-Cell

The use of the Fission-Electric-Cell as a direct collection device is impractical, but if fission fragmenis are mentally replaced with alphas or betas, it is easy to envision an Alpha-Electric-Cell or a Beta-Electric-Cell that will work.

As shown in Fig. 1, the FEC is simple in principle. Fission takes place in a uranium layer on one plate. The charged fission fragments emerge with a net electrical charge of about $+20 \mathrm{e}$. One tries co collect them on the collector plate. A quick mental calculation for fission fragments having an average energy of approximately $80 \mathrm{MeV}$ and an average charge of $+20 \mathrm{e}$ shows voltages of 4 million volts. This is a problem. These voltages cannot be controlled, especially in the radiation field that would be present in such a cell. 


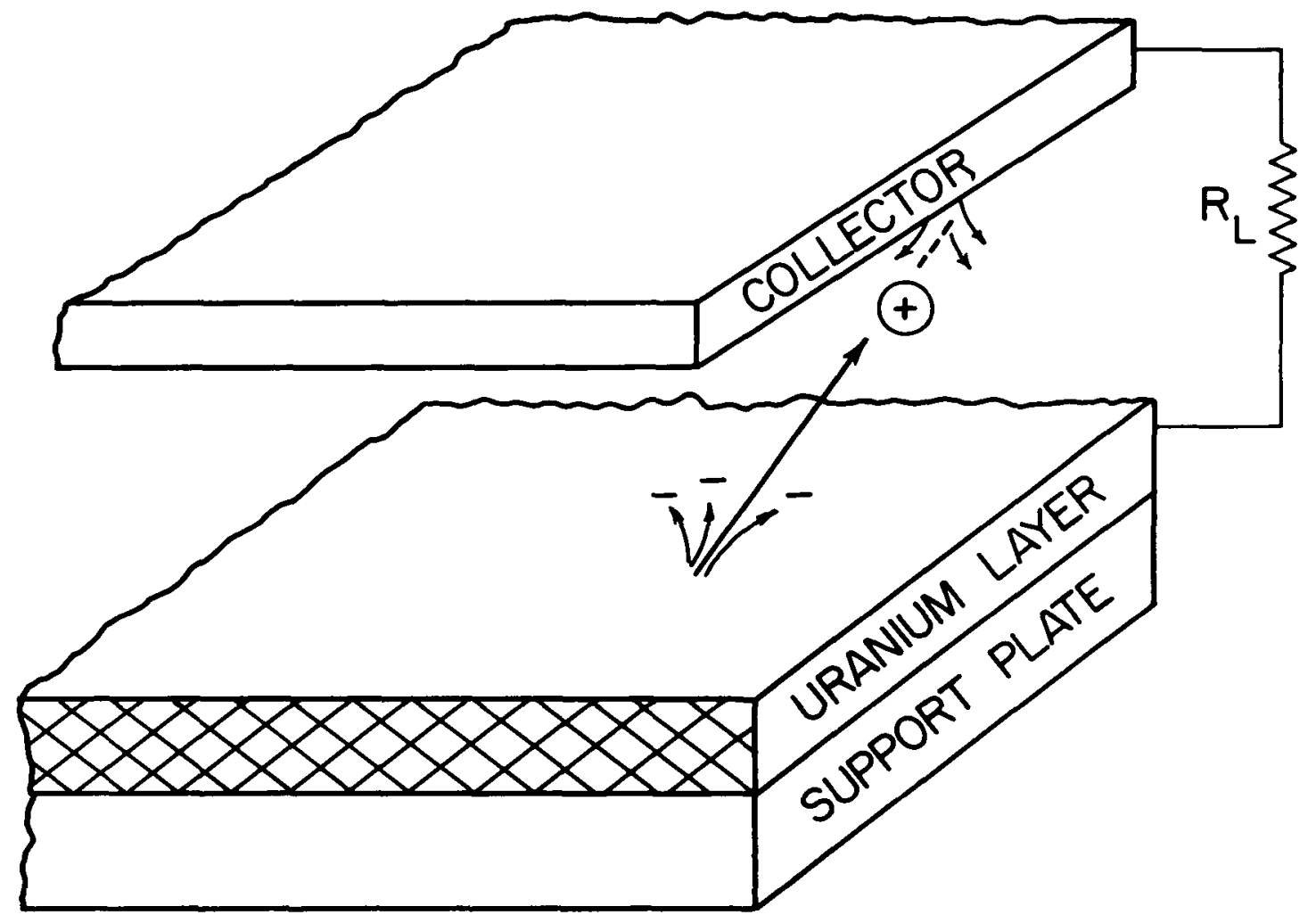

Fig. 1--Parallel plate fission-electric cell. 
The FEC concept was first proposed in 1944 by Wigner. It was not considered seriously, however, because it appeared to be equivalent to bullding a vacuum tube reactor. All the space between plates had to be hard vacuum to provide electrical insulation and also to prevent energy losses from the charged particles traversing the space. In 1957 after some work on a cavity reactor, Safonov realized that it would be 1 deally mated to the FEC. 12 The cavity reactor concept involves the low density region in the center, and this could be envisioned as a space containing the cells. This would lead to practical weight and uranıum requirements.

Figure 2 shows Safonov's early design for such a reactor. It was designed to produce $\sim 200 \mathrm{MW}$ with a critical mass of $8 \mathrm{~kg}$ of uranium-235. It illustrates a basic principle which should be stressed. The FEC does not represent a heat cycle. Thus it is not limited by Carnot efficiencies, so for efficiency purposes the temperatures are not important. Thus Safonov concentrated on the possibility of a low temperature reactor $\left(<120^{\circ} \mathrm{C}\right)$ so he could select materials with optımum neutronic characteristics. He selected aluminum, magnesium, etc. for the structure.

The low temperature approach has not been pursued in recent years. The opposite extreme appears attractive for space applications. In this case the waste heat radiator for a nuclear power supply could run at almost the same temperature as the reactor without harming the cycle effic1ency. Both temperatures would be high, approaching material limits. This would minimize the radiator weight which is important, since in space applications, the radiator is a key item in the overall system weight. A number of conceptual designs of this type have been investigated in some detail at both Battelle Memorial Laboratory and the Jet Propulsion Laboratory. 13, 14 Their results were moderately encouraging.

Consider Figs. 3 and 4 as a simple calculation of the efficiency of a planar cell. Basically the problem is that during fission, the fission fragments are produced with an isotropic angular distribution. Thus half of the fragments go in the direction of the emitter (cathode) support plate and are absorbed or lost there immediately. Also particles with too large an angle $\theta$ will not have a large enough velocity component in the $\mathrm{x}$-direction to reach the anode when it is at a high potential. The maximum allowed value for a simplified case is calculated in the figure. Following the simple energy and momentum balances indicated, the efficiency is found to be $1 / 2(1-\sqrt{\beta}) \beta$ where $\beta$ represents the voltage normalized by the maximum allowed voltage for an open circuit. This result is plotted in Fig. 5. A maximum efficiency of $7^{+}$ per cent is seen to occur at $\beta_{\sim} \quad 1 / 2$, or approximately 2 million volts.

This is a highly idealized calculation. In effect it gives an upper limit for a planar cell. It might be said that the whole concept seems low, but one should take a second look and ask what has happened? After all, this concept is not limited by Carnot efficiencies, so why hasn't a higher efficiency been found? The answer goes back to the emission characteristic, isotropic emission. As already noted, half of the fragments were automatically lost in the support plate. Others with the wrong angle just were not energetic enough to get to the collector. In contrast, if all of the fragments came out perpendicular to the fuel layer it is easy to see that this idealized calculation would show 100 per cent efficiency. 


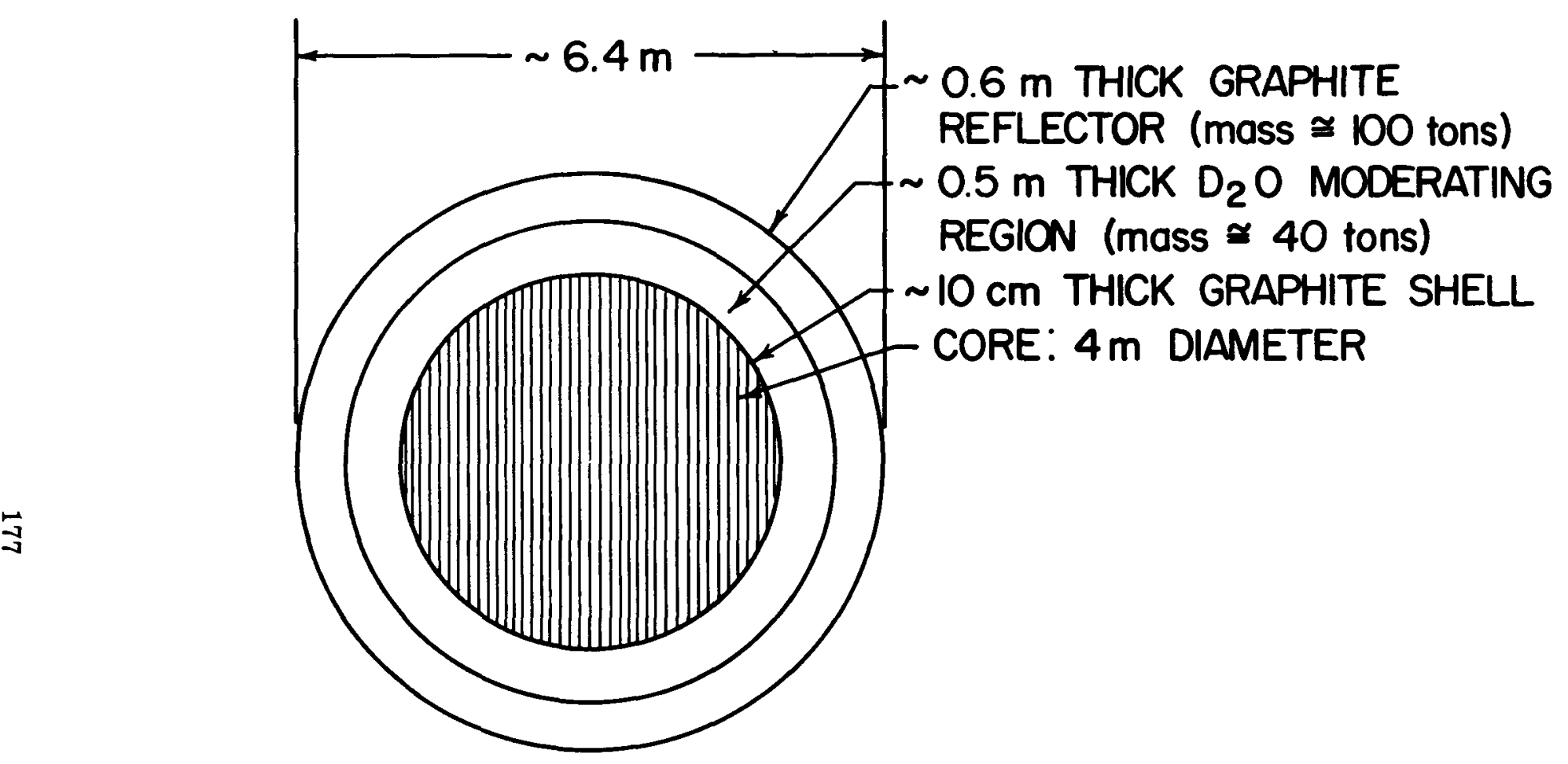

Fig. 2--A low temperature reactor for the direct production of electricity from fission (after Safonov, Ref. 12). Vacuum region contains $\sim 20$ positive and $\sim 20$ negative electrodes alternately spaced with $\sim 10 \mathrm{~cm}$ vacuum gaps. Negative electrodes are coated with $2.4 \times 10^{-3} \mathrm{~g} / \mathrm{cm}^{2}$ uranium-235. Electrodes may be laminar or concentric cylinders and are internally cooled by $\mathrm{D}_{2} \mathrm{O}$. The critical uranium-235 mass is about $8 \mathrm{~kg}$. 


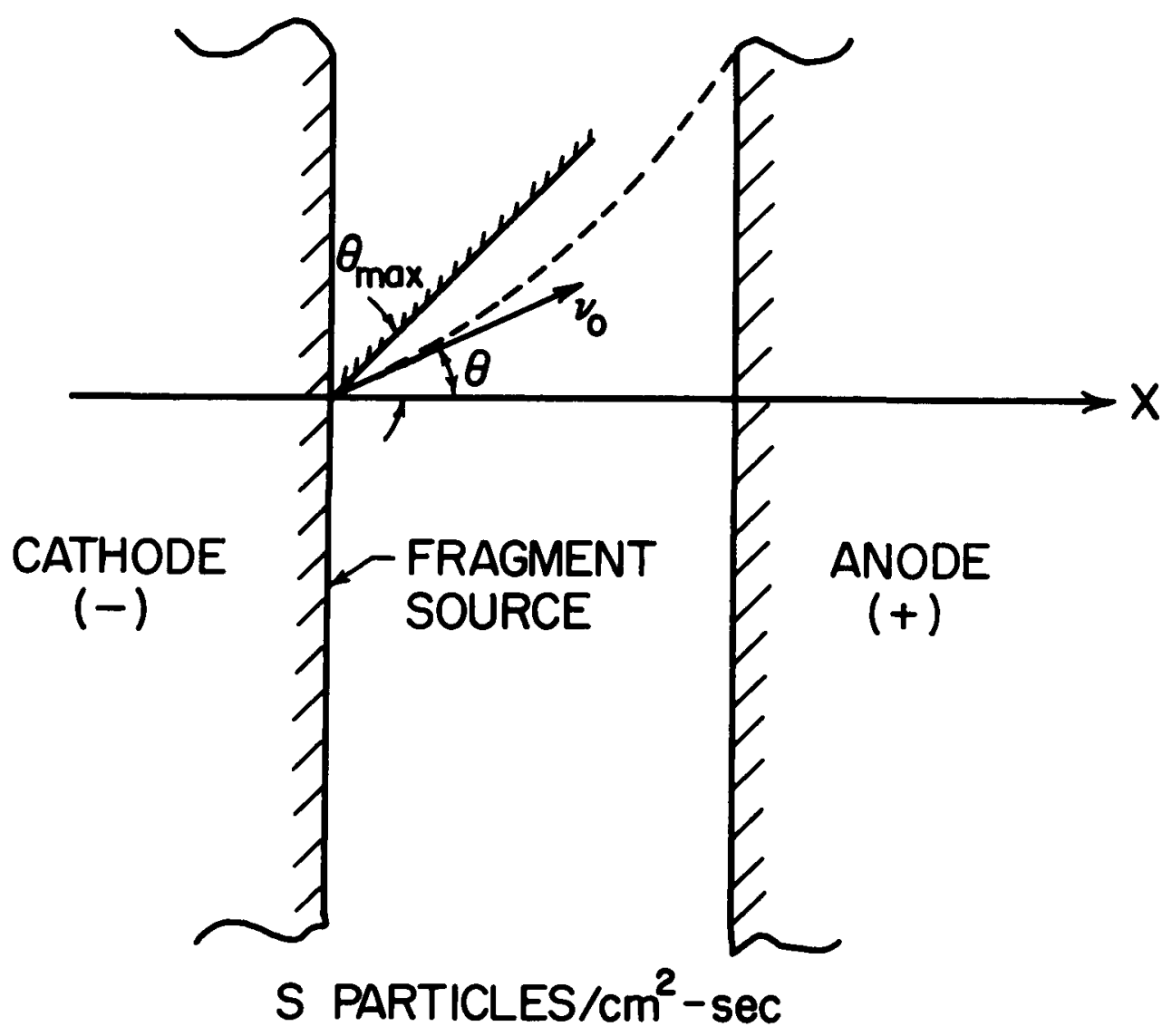

Fig. 3--Idealized cell geometry.

178 
a) MAXIMUM ANGLE OF EMISSION, $\theta_{\max }$

$$
\begin{aligned}
& \nu_{x}=\nu_{0} \cos \theta ; E_{x}=E_{0} \cos ^{2} \theta \underset{\min }{\longrightarrow} U^{+} \overline{\mathrm{e}} \\
& \text { or } \cos ^{2} \theta \geq\left[\frac{U^{+} \bar{e}}{E_{0}}\right]=\beta ; \theta_{\max }=\cos ^{-1} \sqrt{\beta}
\end{aligned}
$$

b) NUMBER REACHING ANODE, I

$$
\begin{aligned}
I & =\frac{\text { AREA }}{\begin{array}{l}
\theta=\theta_{\max } \\
\theta=0
\end{array}} \text { TOTAL AREA } \\
& =\frac{1}{2}(1-\sqrt{\beta}) \mathrm{S}
\end{aligned}
$$

c) EFFICIENCY, $\eta$

$$
\begin{aligned}
\eta & =\frac{I \cdot(\Delta K . E . / \text { PARTICLE })}{\text { TOTAL EMITTED } \cdot(\text { INITIAL K.E. })} \\
& =\frac{\frac{1}{2}(1-\sqrt{\beta}) \$ \cdot U^{+} \overline{\mathrm{e}}}{\$ \cdot E_{0}}=\frac{1}{2}(1-\sqrt{\beta}) \beta
\end{aligned}
$$

Fig. 4--Efficiency of an idealized cell

Assume: plane electrodes; zero fuel thickness;

all fragment to support plate loss;

single energy (Eo) and charge (e) fragments;

perfect grid; and neglect beta decay effects. 


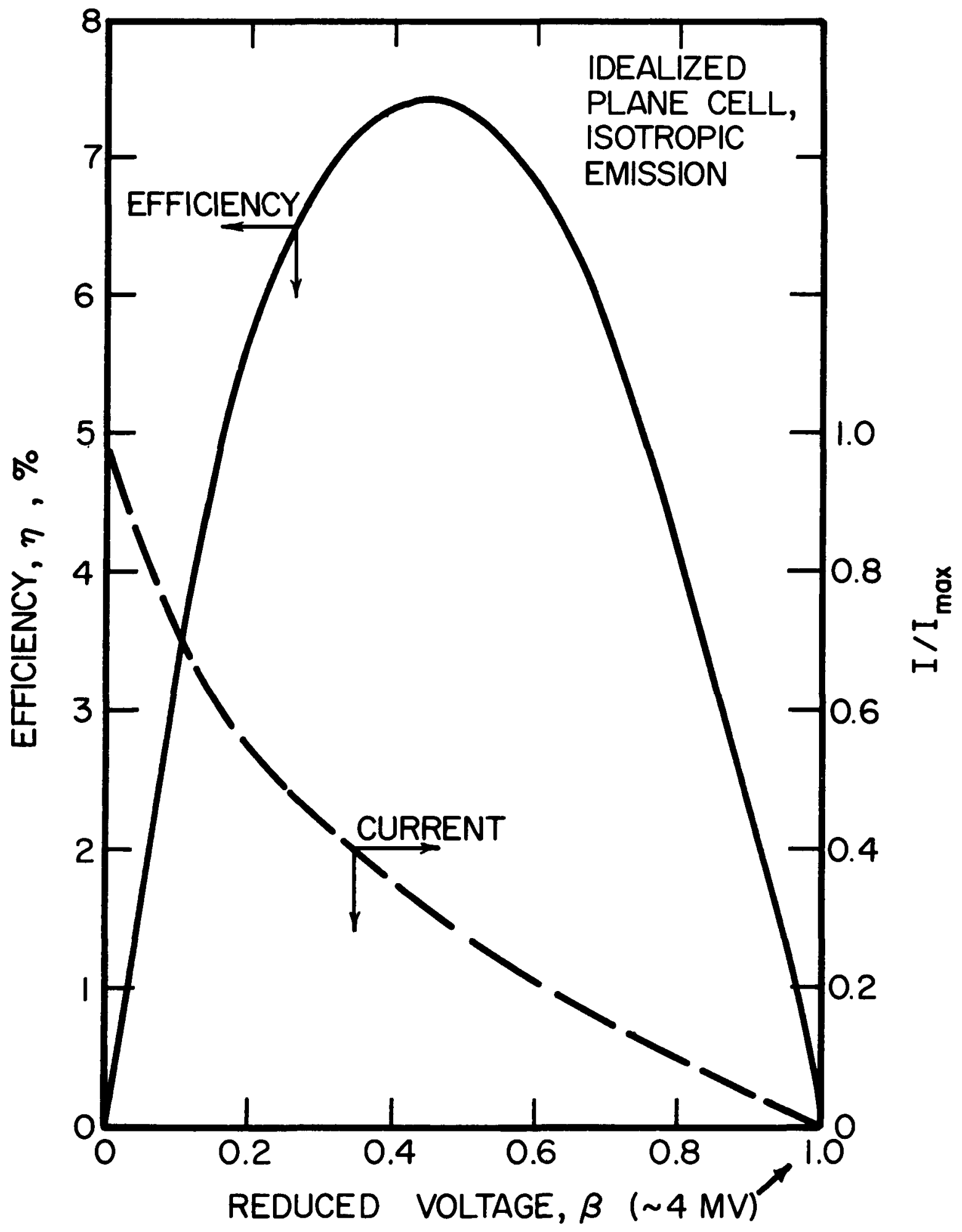

Fig. 5--Efficiency and current vs. reduced voltage. 
This is perhaps not so far fetched as it seems. One way to approach this ideal would be to go to a spherical geometry. If a point emitter were used, regardless how the fragment came out, it would always have its velocity component directed toward the collector, and this too would give 100 per cent efficiency.

The effect of geometry on efficiencies is summarized in Table II.

TABLE II

Maximum Efficiencies

\begin{tabular}{lcr} 
Geometry & $\begin{array}{c}\text { One-sided } \\
\text { Emission }\end{array}$ & Two-sided \\
\cline { 2 - 3 } Plane & 7.4 & 14.8 \\
Cylindrical & 19.2 & 38.4 \\
Spherical & 50.0 & 100.0
\end{tabular}

Advantages

Space - nonthermal cycle $\rightarrow$ minimum radiator, high power/wt.

- high voltage for ion-propulsion without conversion equipment

- rugged, no moving parts

Other - possible low temp cycle $\rightarrow$ improve neutron economy

- pulsed or ac operation possible

- toppıng cycle

In the spherical case, half of the fragments may still be lost to the support structure necessary for the emitter in which case the 100 per cent efficiency noted above drops to 50 per cent (this is labeled "one-sided" emission). Similar arguments hold for the cylindrical configuration.

This is an important result because one wants to look at the upper limit. While no one has come too close to the se ideal efficiencies, they illustrate goals. The best efficiency was reported by Linder and Christian in 1952 using a Beta-Electric-Cell. 15 This was a low-power cell in the mill1watt range, but it produced over 300,000 volts with a measured efficiency of approximately 30 per cent. 
It is a tantalizing thought that quite respectable efficiencies are prevented only by ingenuity in the design and understanding of the phenomena that occur.

Some advantages for the concept are listed in Table II. They usually revolve around the nonthermal characteristics of the cycle, e.g., the minimum radiator weight, reliability, etc. The importance of these factors should not be overlooked. They may in fact be more significant in some applications than efficiency.

Figure 6 summarizes some of the complicating features which will cause deviations from the ideal case. One of the basic problems in direct collection has to do with the transport of the charged particles through the source material. The situation is this The fragments have a range of order of 10 microns in uranium. Thus even for a thin coating energy losses will be significant. The problem is then to understand how to get them out of the uranıum layer most efficiently and predıcting how much energy they have left after they get out.

In addition one has to worry about secondary electron emissions from the surface as the fragment leaves. It turns, out that more secondary electrons emerge than do fragments, and in fact the net negative to positive charge ratio is approximately 20. If the secondary electrons are not stopped from reaching the collector, a negative charge will build up instead of the desired positive charge, which is undesirable. The secondary electrons have low energies, so if they are collected, the device won't work efficiently. Thus a grid or magnetic field must be added to turn the secondaries around.

One must worry about sputtering. When a fragment rams into a surface, pieces of the surface come off--both neutral and ionized particles-and this may also cause leakage currents, and in the extreme case voltage breakdown.

The experiments that have been done are complex, and to date an experiment that appears suitable for university research has not been devised.

Figure 7 shows a triode cell which was studied at the Battelle Memorial Institute. It is called a triode cell because of the squirrel-cage type grid structure which turns back the secondary electrons. This design has been run in the Battelle research reactor for approximately 200 experiments. A typical result is shown in Fig. 8. The net current should be positive for useful power production. However in this case the curve, for some unexplained reason, goes negative above about 1800 volts on the grid. In this and a number of similar attempts, output voltages were always less than a hundred or so volts out of a possible 4 million. This caused the investigators to question the validity of the basic concept. To test this and to explore new areas, similar cells were built with beta and alpha emitters and successful voltages were achieved. Thus it seems that there are some phenomena in the FEC which are not yet completely understood.

Figure 9 shows the cell used in experiments that were done at JPL by Krieve, Heindel and others. 17 They used a magnet to turn around the secondary electrons, rather than a grid. This cell was put in a reactor, 


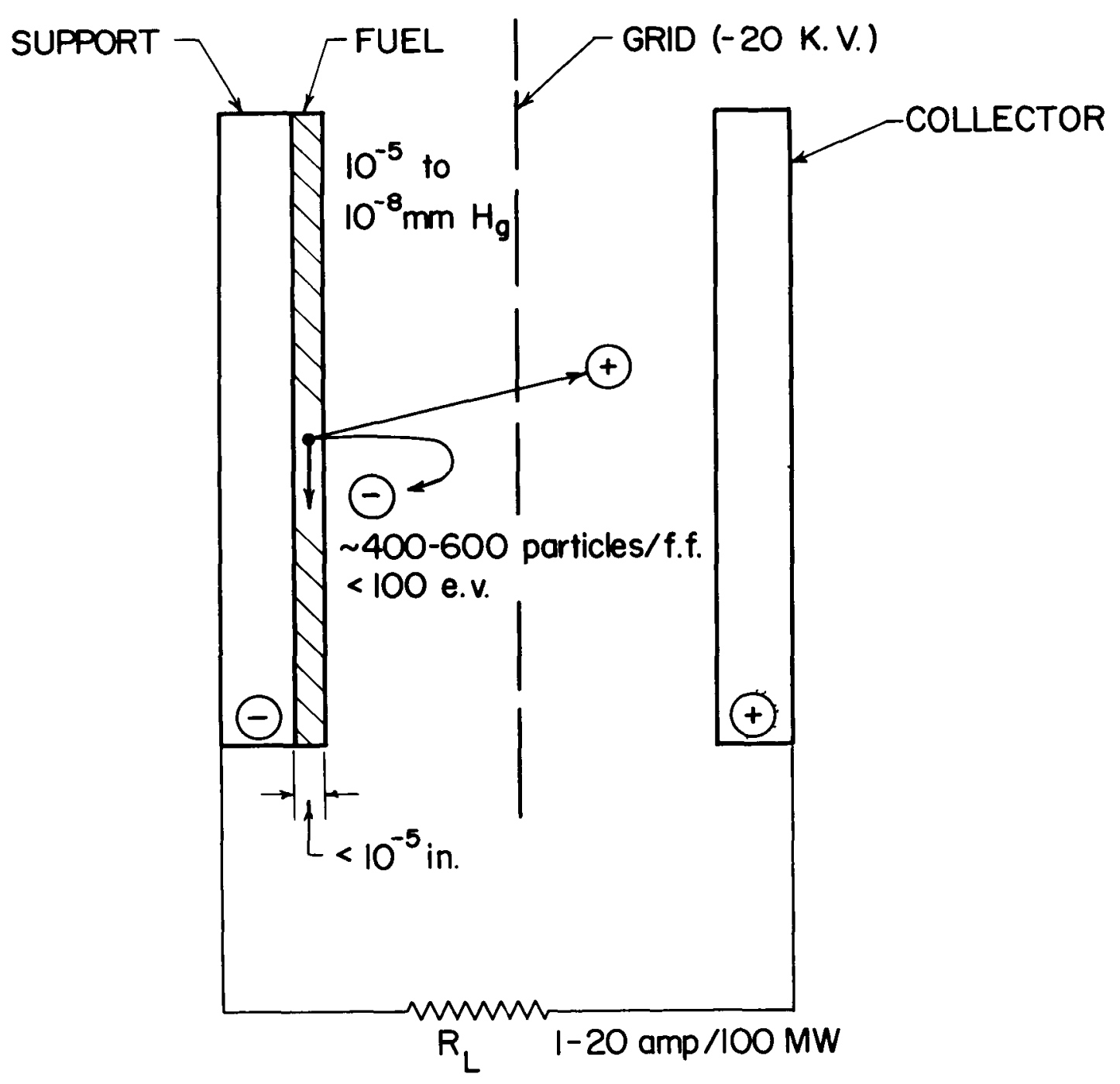

Fig. 6--The Fission-Electric-Cell illustrating the requirements of (1) thin fuel, (2) hard vacuum, and (3) grid. 

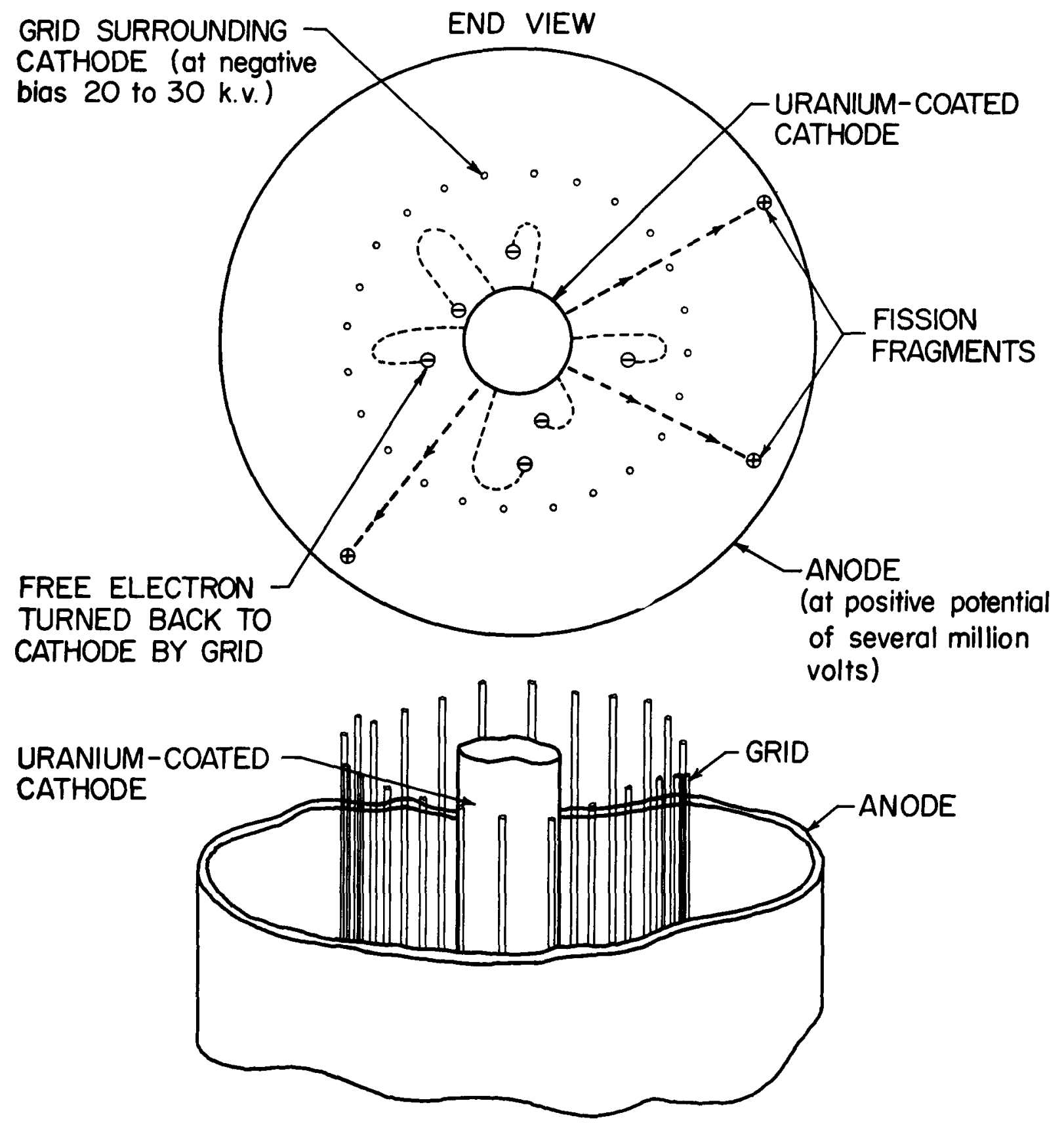

SECTION OF SIDE VIEW

Fig. 7--Sketch of a cylindrical triode cell (after Plummer and Anno, Ref. 16). 


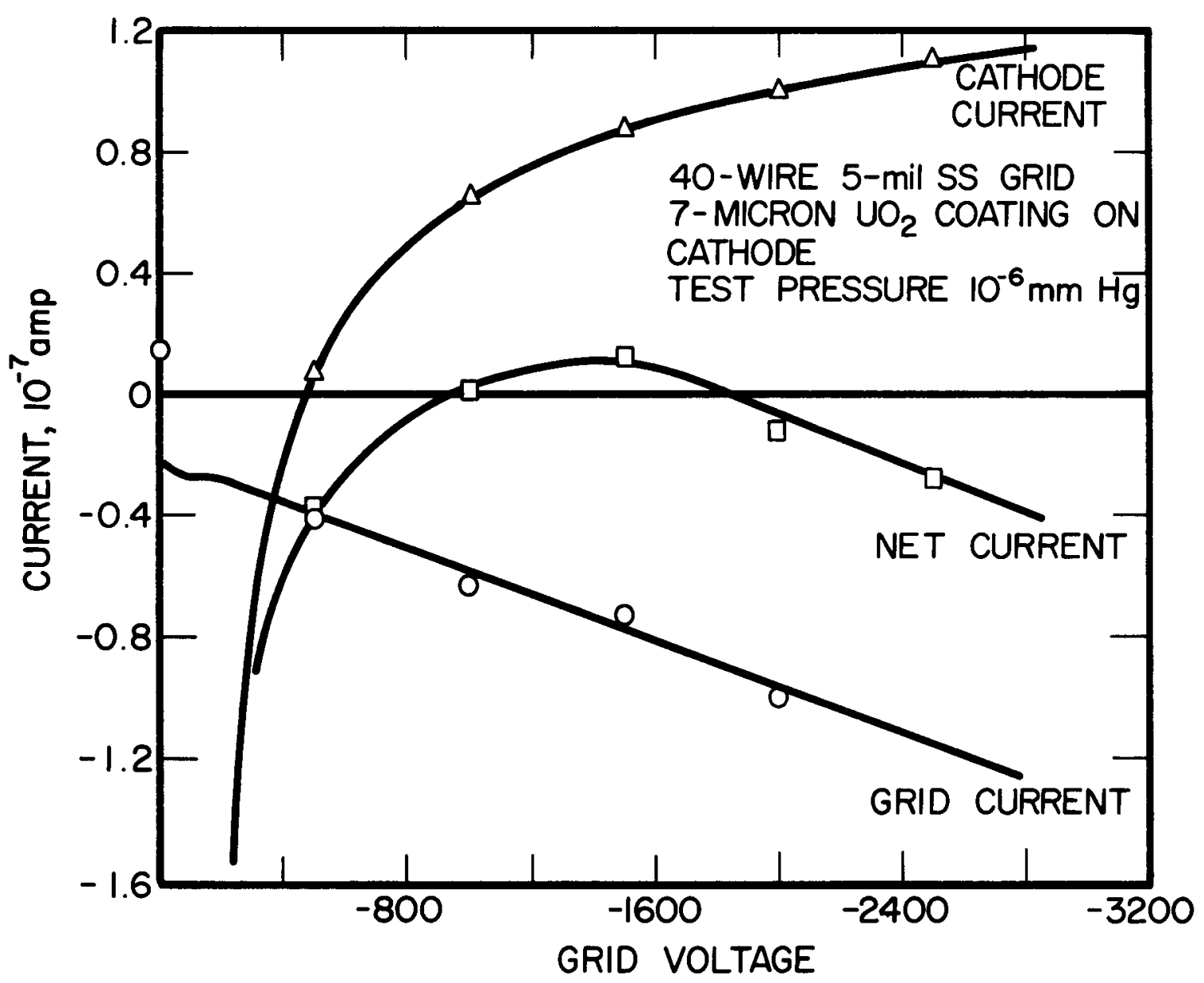

Fig. 8--Typical current behavior of triode cell (after Plummer and Anno, Ref. 16). 


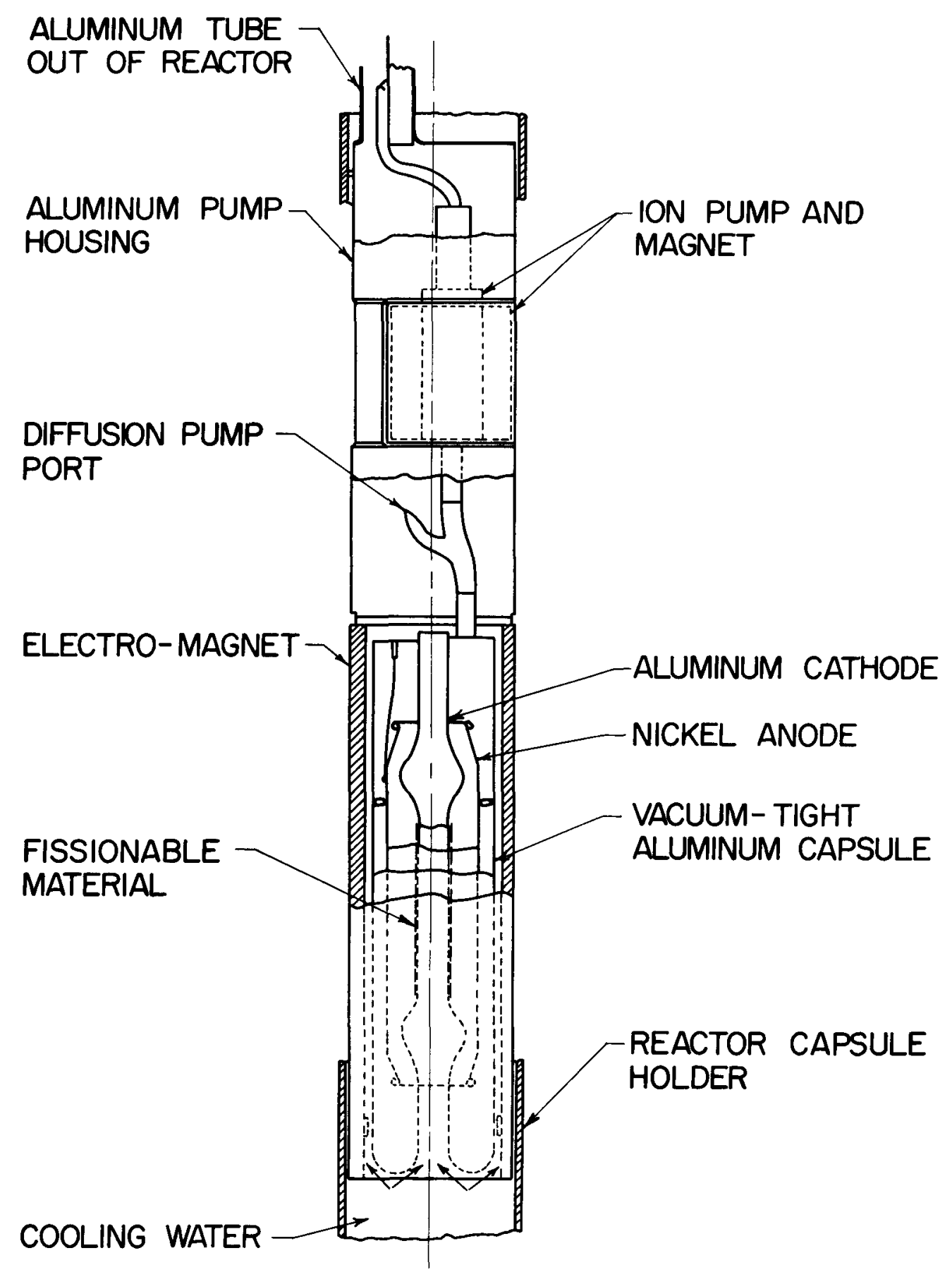

Fig. 9--Fission-Electric Cell capsule (after Krieve, Ref. 17). 
and again no voltage build up was observed. These studies continued for several years until the cell design shown in Fig. 10 finally evolved. A fairly successful voltage build up was achieved with it, as shown in Fig. 11.

This design presents several important points. First the emittercollector configuration was inverted, the emitter being on the outside (compare to Fig. 9). Also additional electrodes called sweep rings were added. These electrodes were conceived based on the following logic Krieve proposed that voltage build up did not occur due to a sputtering problem. He suggested that sputtered material produced as the particles hit the collector might in turn be ionized by collision. Trapped electron densities may be high enough so that lonizing collisions would be favored. Specifically, secondary electrons suffering energy losses while in the magnetic field region cannot return to the emitter. They would be trapped in the interelectrode space, spin around for a while and perhaps ionize sputtered material while drifting toward the collector. This would create an unwanted plasma in the vacuum space between the two electrodes, resulting in leakage currents. The sweep rings were designed to provide a positive potential to sweep out trapped electrons. Also inverting the electrode geometry minimizes electron paths, hence, reducing the collision probability. As shown in Fig. 11, a potential of 20,000 volts was achieved with a 60 amp magnetic field current. This is stıll well below the million volts discussed earlier, but as illustrated in the figure, the calculated curves and experimental data agree fairly w oll, at least in slope. On this basis Krieve argued that had larger field currents been avallable, higher voltages could be obtained. While the above may explain the fallure to achieve voltages in devices using magnetic secondary suppression, it stıll does not explain the trouble with cells using grids. Unfortunately, the latter may be the most practical from the point of view of size and weight.

This completes a brief discussion of the FEC. Alpha and beta cells have also been built which exhıbited certain advantages and disadvantages. One major point to note is that the beta emitters involve lower energy particles, so they can operate efficiently at relatively low voltages, this gets around some of the voltage problems. As noted earlier Linder and Christian achieved 30 per cent efficiency at 300,000 volts.

The only active project involving a high power cell is a Beta-Cell study in progress at NASA Lewis Laboratories where the cell is of interest for electric propulsion schemes. 18 A number of companies produce low power cells, commonly called "nuclear batteries."19

\section{B. Direct Collection Studies}

The approach at the University of Illınois has generally been to select some specific aspect for detalled study rather than attempt to study the device as a whole. (One exception to this rule is the work with the GammaElectric-Cell. ${ }^{20}$ )

A number of varied calculations in the area of charged particle transport were made. 21 An illustration of some results related to fission fragment transport is shown in $\mathrm{F}_{1 \mathrm{~g}}$. 12. Here $\mathrm{n}_{j}, \mathrm{~s}_{\mathrm{j}}$, and $\mathrm{m}_{j}$ are parameters related to the energy-charge loss law used in calculating fragment slowing. Without explaining this figure in detall, the main point illustrated is that the 
FUEL ELEMENTS AND SWEEP RING (0.015 in.

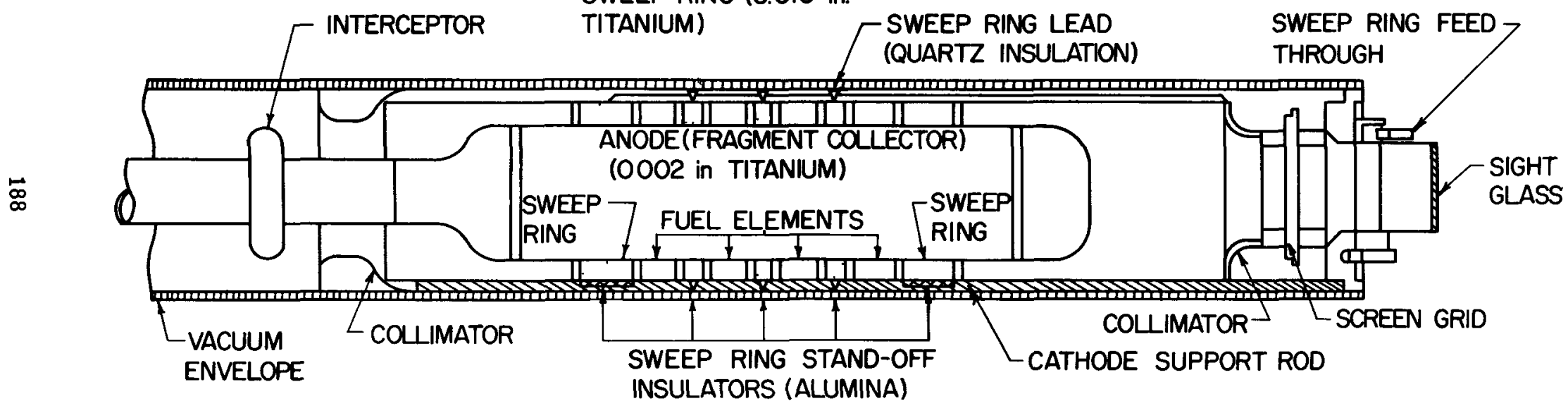

Fig. 10--The modified FEC capsule (after Krıeve, Ref. 17). 


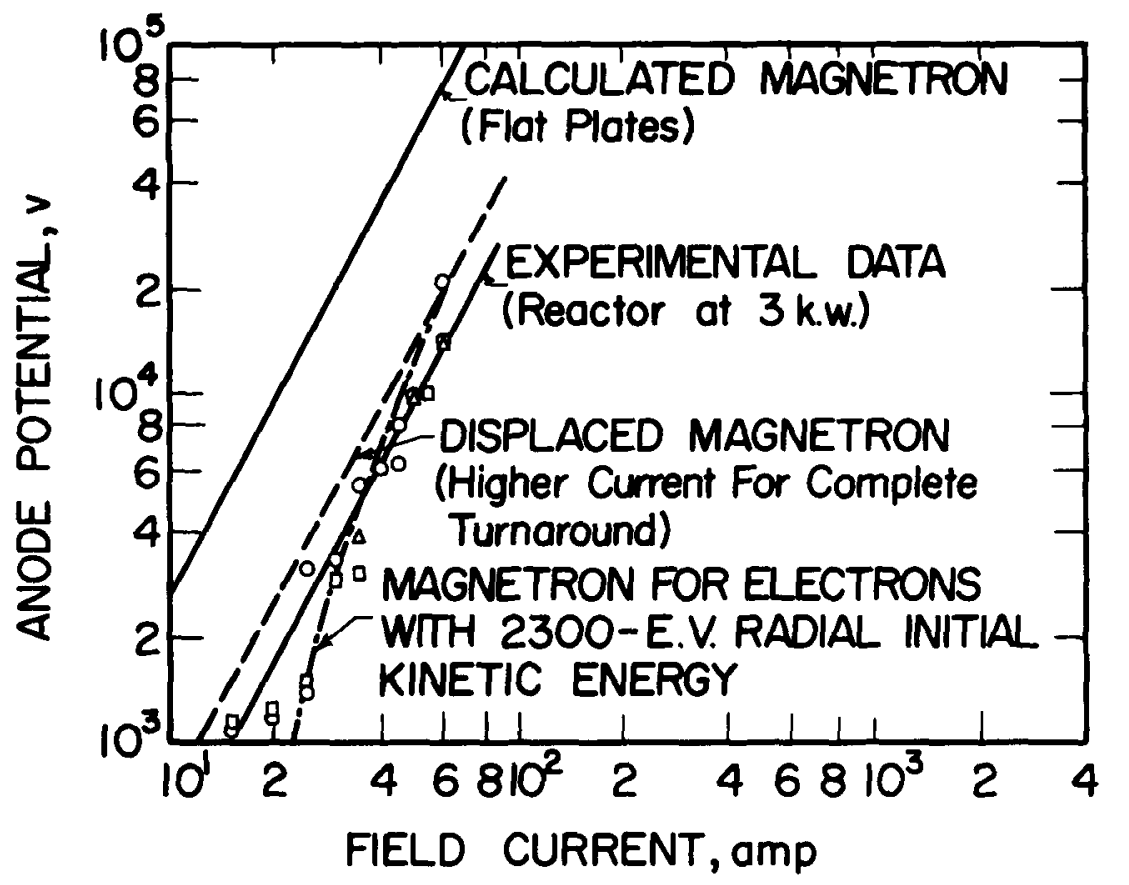

Fig. 11--Open-circuit potential as a function of magnetic field current, modified FEC capsule (after Krieve, Ref. 17). 


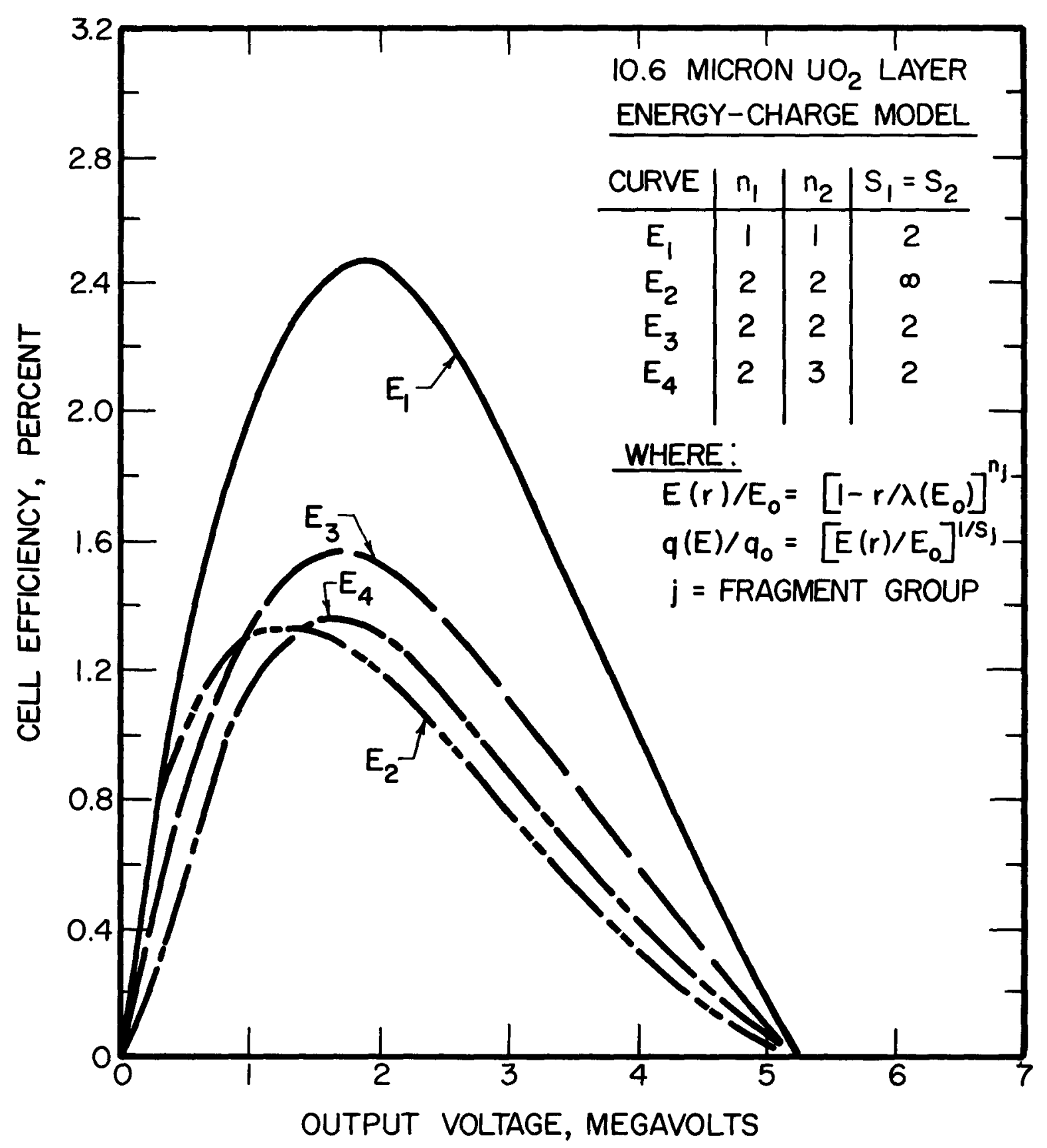

Fig. 12--Efficiency calculations for a thick fuel (after Miley, Ref. 22). 
treatment of particle transport is an important problem in efficiency calculations. Not only is this true in direct collection devices but also in the ionization cells where one is interested in obtaining charged particles from the fuel layer and putting them into the fluid to produce ionization and/or excitation. These problems are also of interest to other areas such as space shielding. Thus this area is one where significant work can be done in universities, and where there are still a number of remaining problems. As an example, there is a problem in doing calculations leading to Fig. 12. The calculations were compared with the avallable experimental data. There are two ways of doing the experiment. One is a transmission type measurement of the energy loss of the charged particle as it passes through folls of various thicknesses. The other is a measurement of the energy spectrum of the fragment current leaving fuel layers of various thicknesses. The latter in effect is an integral measurement while the transmission measurement might be viewed as a differential measurement. There are major discrepancies between the best experıments using these two techniques. Some careful studies are needed to resolve this problem.

Another area of transport theory that has received attention is secondary electron production. The problem is illustrated schematically in Fig. 13. Consider a primary particle such as a fission fragment entering (or leaving) a surface. It produces a number of electrons, ranging from low to high energies, and one is interested in their formation and then their transport or diffusion to the surface. The higher energy electrons ( $\delta$-rays) may produce further secondaries, and these must be considered also. Then there is the interesting question of the barrier for escape across the surface.

Most of the work to date in this area has been for low-energy incident particles. Fission fragments, alpha particles, etc. With their high energy and relatively high charge represent an open field for research studies.

Some feeling for the situation can be joined by reference to Table III. Several recent calculations and measurements of low energy $(<50 \mathrm{eV})$ secondary electron yields are given. Note that the calculation for the fragment yield is almost an order of magnitude different from that by Anno ${ }^{23}$ although both use the Ionization-Diffusion Model. While the result is closer to experiment, there are sufficient uncertainties involved so that the agreement in this case might still be fortuitous. An older model for such calculations, the thermionic model, is also shown. It clearly gives erroneous results for fragments, but because of their lower charge, alpha particle calculations turn out to give reasonable results.

In conclusion secondary electron production is a complex subject. At present the theory and even the measurements are "fuzzy" when high energyhigh charge particles are involved. It too looks lıke a ripe area for university research.

\section{Nuclear Radiation for Laser Pumping}

As indicated earlier, this has been selected as an example of conversion of nuclear radiation via ionization and excitation, 1.e., following the earlier analogy by many small barriers rather than one large one. 


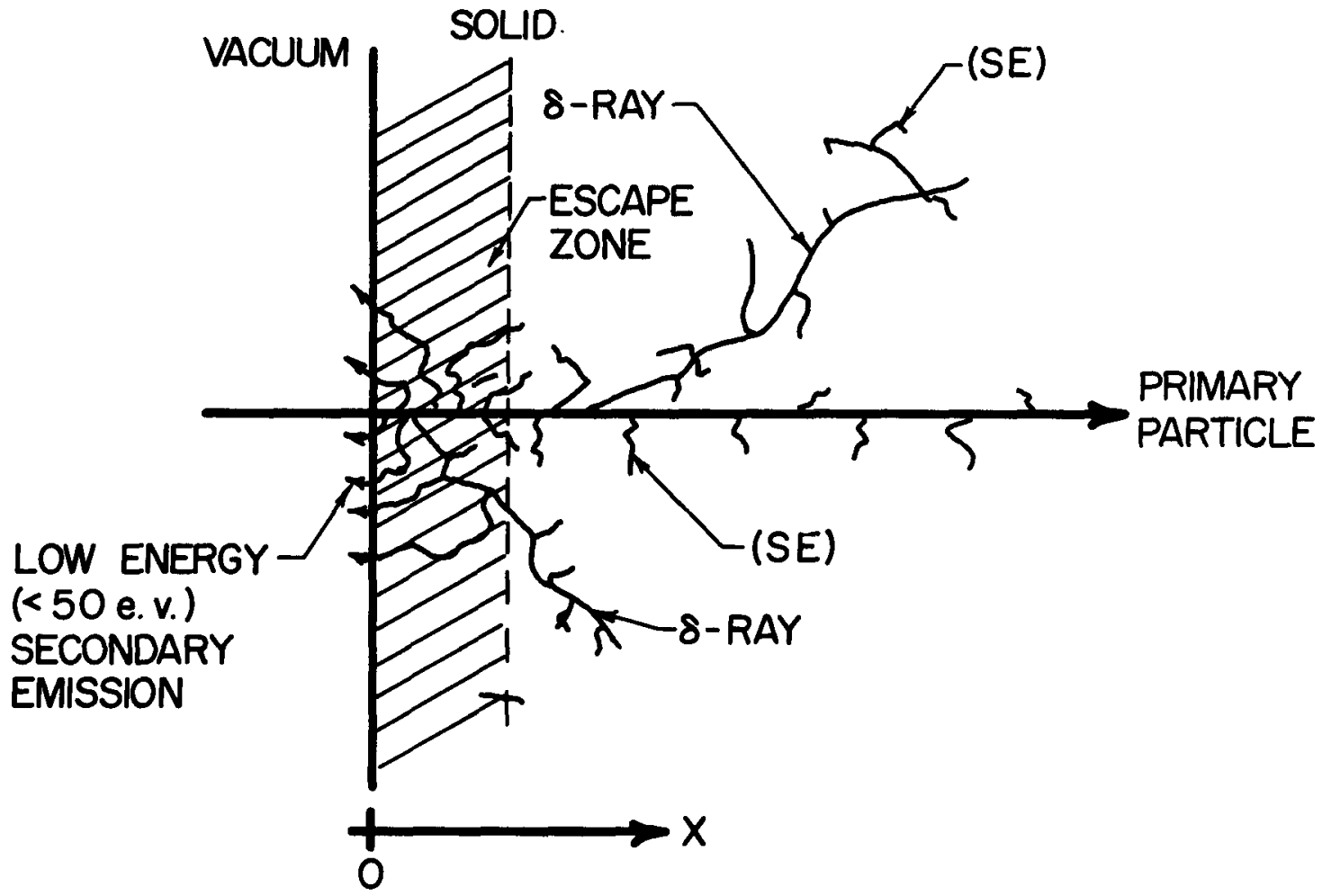

Fig. 13--Formation of secondary electrons (SE) and $\boldsymbol{\delta}$-rays by a high energy charged particle. (The shaded area indicates the escape depth or "zone" for secondary electrons.) 
TABLE III

Calculated and Experimental Yields

\begin{tabular}{|c|c|c|c|c|c|}
\hline \multirow{2}{*}{\multicolumn{2}{|c|}{ Target }} & \multirow[b]{2}{*}{ Particle } & \multicolumn{3}{|c|}{ Yield (Normal Incıdence) } \\
\hline & & & $\begin{array}{c}\text { Measured } \\
(\text { Ref. } 21) \\
\end{array}$ & I-D Model & $\begin{array}{c}\text { Thermionic } \\
\text { Model }^{(4)}\end{array}$ \\
\hline \multicolumn{2}{|c|}{$\mathrm{Au}$} & Alpha $(\sim 3 \mathrm{MeV})$ & 5.5 & $\begin{array}{l}5.7^{(2)} \\
8.8^{(3)}\end{array}$ & 5.8 \\
\hline \multicolumn{2}{|c|}{$\mathrm{UO}_{2}$} & Fission Fragment & 118 & $\begin{array}{ll}800 & (2) \\
196 & (3)\end{array}$ & $7.7 \times 10^{4}$ \\
\hline $\begin{array}{l}\text { (1) } \\
(2) \\
(3) \\
(4)\end{array}$ & \multicolumn{2}{|c|}{$\begin{array}{l}\text { Corrected for geometry, } \Delta^{\mathrm{f}} \\
\text { (p. } 58, \text { Ref. } 23 \text { ). } \\
\text { Values reported by Anno ba } \\
\text { cal/cm for Au and } \mathrm{UO}_{2} \text { res, } \\
\text { Calculations by } \mathrm{M}_{1} l e y, \text { Ref. } \\
\text { Calculations by Anno using }\end{array}$} & \multicolumn{3}{|c|}{$\begin{array}{l}\quad \text { obtained from } \Delta^{\alpha} \text { using } R_{\Delta}=21.3 \\
\text { sed on }\left\langle\frac{\mathrm{dE}}{\mathrm{dx}}\right\rangle=2.6 \times 10^{-10} \text { and } 3.4 \times 10^{-9} \\
\text { pectively and }=690 \mathrm{eV} \text { for } \mathrm{Au} \text {. } \\
21 \\
\text { the following constants }\end{array}$} \\
\hline
\end{tabular}

\begin{tabular}{|c|c|c|}
\hline & $\underline{\mathrm{Au}}$ & $\mathrm{UO}_{2}$ \\
\hline $\mathrm{C}_{\mathrm{V}}\left(\mathrm{cal} / \mathrm{gm}^{\mathrm{O}} \mathrm{c}\right)$ & 0.32 & 0.078 \\
\hline $\mathrm{K}\left(\mathrm{cal} / \mathrm{sec} \mathrm{cm}^{\circ} \mathrm{c}\right)$ & 0.71 & 0.0063 \\
\hline$\left(\mathrm{gm} / \mathrm{cm}^{3}\right)$ & 19.3 & 10.1 \\
\hline $\mathrm{cal} / \mathrm{gm}$ & $2.6 \times 10^{-10}$ & $3.4 \times 10^{-9}$ \\
\hline
\end{tabular}

The laser may seem to be an odd example at first thought since it does not produce electrical power. Still by earlier ground rules, it is a perfectly valid subject. Basically, the scheme would convert nuclear radiation to either optical or infrared radiation.

The possibility was first considered in connection with military uses, but these reports have not been obtained. One of the members of the Program Committee for this meetıng, Dr. Herwig, while at United Aircraft produced in 1964 what is a classic report on nuclear pumping of a gas laser. 24 While there were some vague ideas about the problem prior to then, certainly this report "cemented" our thoughts. A basic point that came to light in our studies was that the experiment should be feasible with neutron fluxes such as those achieved during a TRIGA reactor pulse. It was decided in 1965 in cooperation with Professor Verdeyen of our Electrical Engineering Department to begin an experımental program usıng the Illınoıs TRIGA. Several graduate students have been involved and a Ph. D. thesis is in progress. No concrete results have been obtained to date. We have in general attempted to identify specific problems which may be bottlenecks and concentrate on them. (Note added in proof Preliminary results from the in-core helium-neon laser study were reported at a conference in November, 1967.25 Successful operation of a low-voltage-arc laser, described later, was first achieved during September, 1967.26) 
Figure 14 illustrates how a laser works. Consider an idealized two-energy state system. Radiation comıng in "kıcks" an electron from State 1 to State 2 corresponding to the conventional absorption process. Neglecting outside influences, this electron will eventually decay back to the lower level giving up a photon by spontaneous emission However, stımulated emission can also occur. One can bring in radiation with an energy exactly matched with these two levels and get out two photons. Thus the possibility of building a "critical system" becomes evident. The term criticality is used because there is a direct analogy with nuclear reactor criticality. Stimulated emission is analogous to neutron multiplication. A reflector helps the reactor go critical, and in the case of the laser, mirrors are used for this purpose. In the jargon of the field, one places the laser in a resonant cavity.

The University of Illınois has been concentrating on direct methods for coupling lasers and reactors. Gas lasers, e.g., typical helıum-neon lasers, are much less than 1 per cent efficient based on an overall energy-ın, energyout balance. (The $\mathrm{CO}_{2}$ laser is a notable exception where efficiencies well over 10 per cent are possible, but its output is in the $10 \mu$ range which restricts its application.) If one concedes that reactors are going to be in space, and also lasers are going to be in space (for communications, etc.) it seems it would be important to couple them in the most efficient, reliable manner possible.

Figure 15 illustrates two separate paths. The conventional laser cycle would use heat from the reactor in connection with a conventional stream or liquid metal-electrical generator cycle, and then a conditioning step to produce high voltage ( $\mathrm{kV}$ range) or $\mathrm{rf}$ whıch would actually pump (supply ene rgy to) the laser.

A more simple cycle, also shown in Fig. 15, involves heat generation, but the heat would then be used to drive a thermionic discharge. Such a discharge produces a nice plasma if it is designed properly, and there is a good chance this plasma can lase. There are some horrendous problems to actually building an in-core device If people working on in-core thermionic devices can make these work, the extension to an in-core low-voltage-arc laser is not too great. A long this line it might be noted that cesium has lased (but under optical pumping), so there remains a possibility of a combined thermionic energy conversion--laser cycle.

The last cycle shown in Fig. 15 is even more direct. Here fission fragments, alphas or other charged particles produced by neutron interactions are used to conize and excite the gas. In the conventional cycle electrons accelerated by an imposed voltage or rf signal produce the ionization and excitation. Thus, the fission fragments or alphas simply replace the se electrons. This may not seem like much of a step, but the re are some subtle differences. In order to appreciate this, let us first review the helium-neon energy level diagram illustrated in Fig. 16.

The lasing levels (three are possıble $3.39,1.15$ and $0.63 \mu$ ) are actually located in neon. Helium is used as a convenient means of transferring energy to the desired neon levels. Helium is excited by collisions into $2^{1} \mathrm{~S}$ or $2^{3}$ S states which are metastable. Subsequent collisions transfer this energy to neon as illustrated, so that lasing may occur between one or more of the 


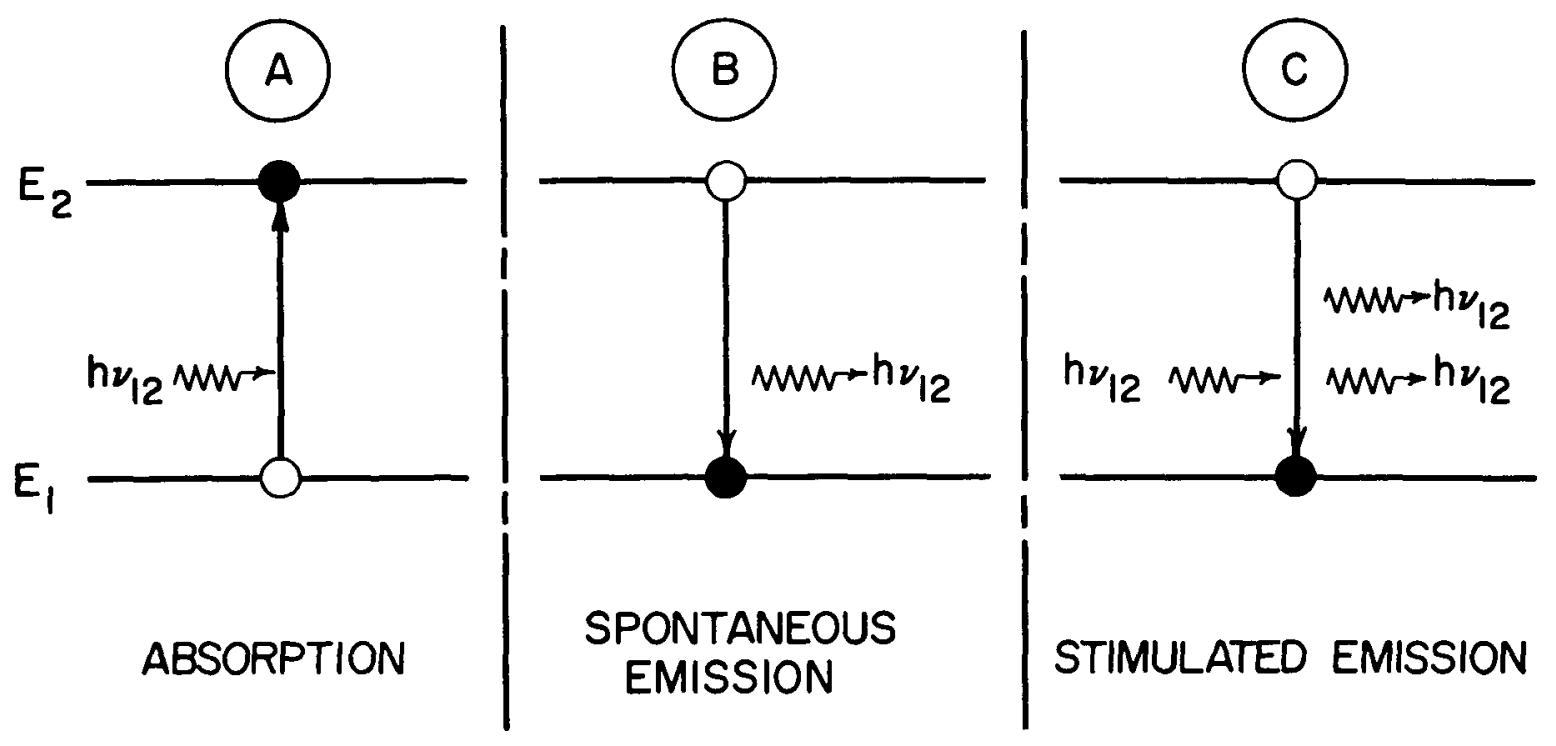

$$
I=I_{0} e^{r x}
$$

WHERE: $\quad$ $\propto \propto\left(n_{2}-n_{1}\right)$

$\therefore \gamma<0 ; n_{2}<n_{1}$ (ATTENUATION)

$$
r>0 ; n_{2}>n_{1} \quad \text { (AMPLIFICATION) }
$$$$
n_{2}>n_{1} \equiv \text { POPULATION INVERSION }
$$

Fig. 14--The concepts of stimulated emission and population inversion. 


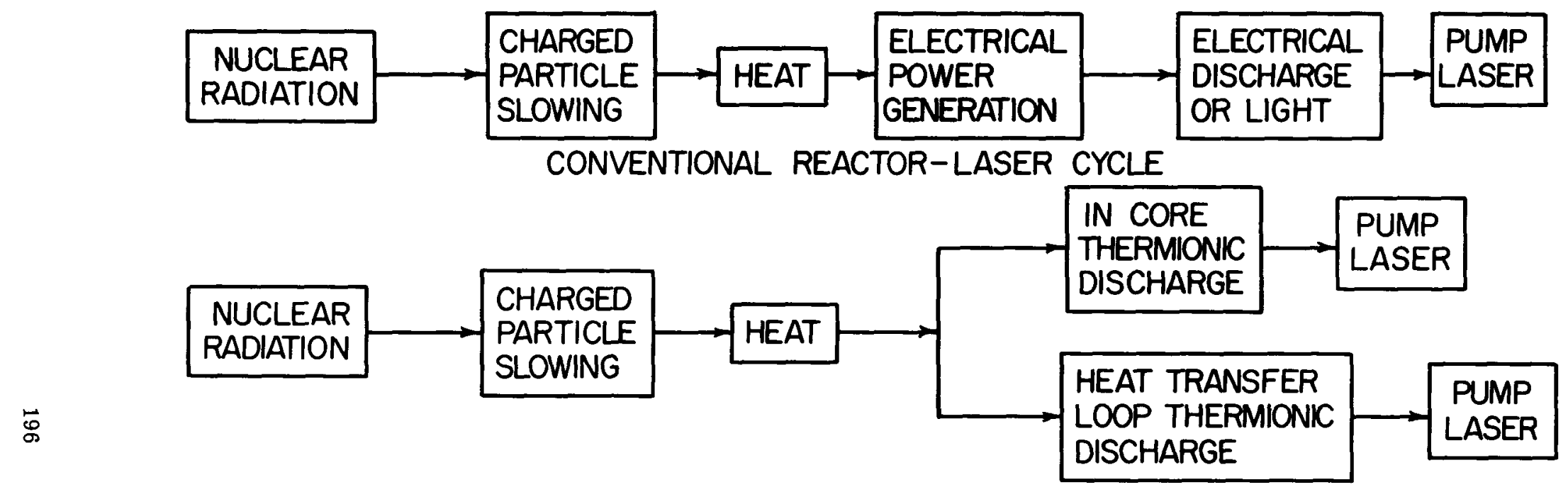

LOW-VOLTAGE ARC REACTOR-LASER CYCLE

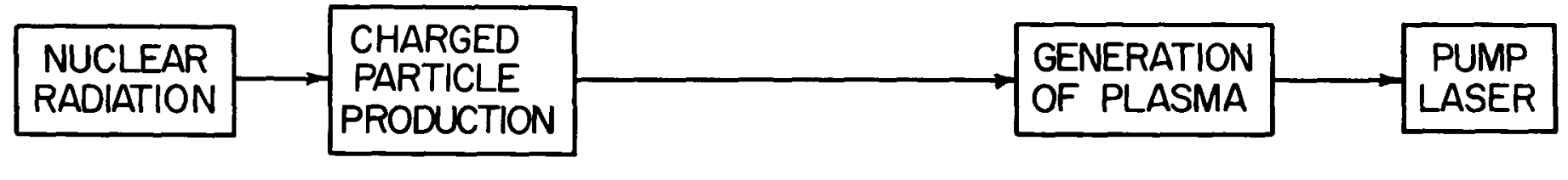

DIRECT PUMPING REACTOR-LASER CYCLE

Fig. 15--Laser pumping cycles. 


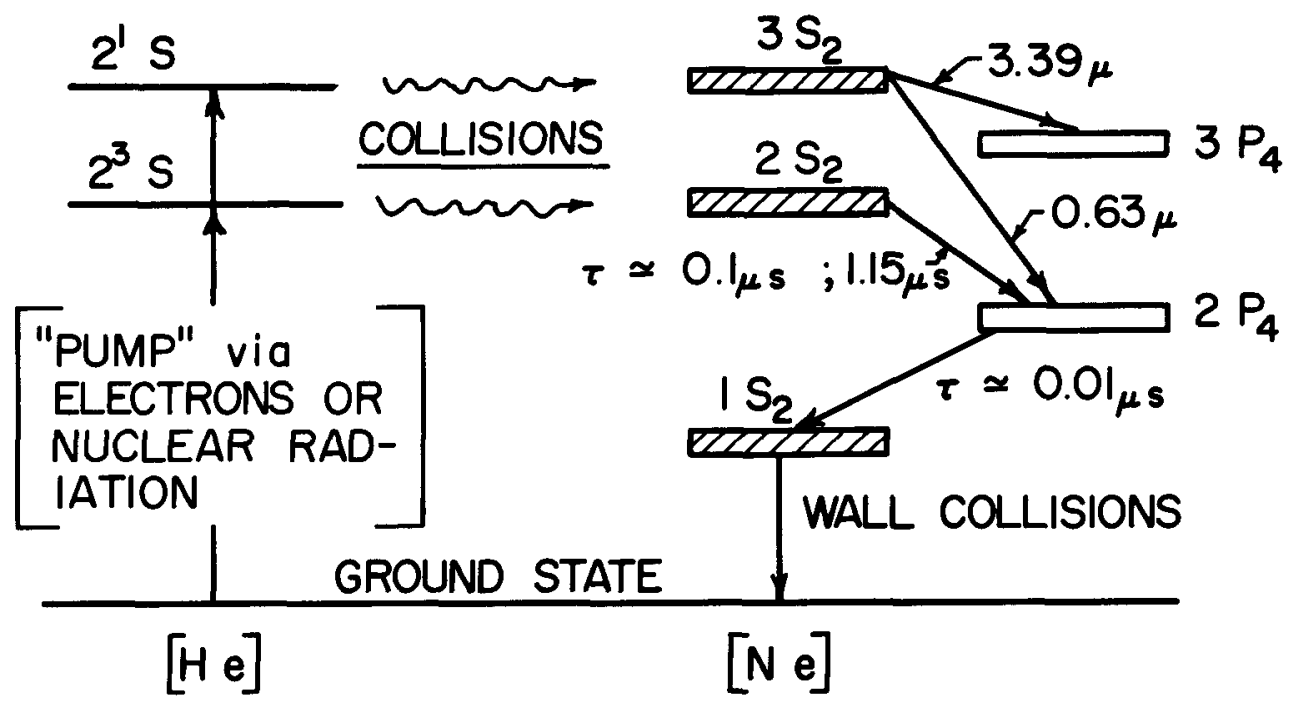

Fig. 16--The helium-neon gas

Key 1 Neon emits at desired frequencies, 1.e., 1.15 or $3.39 \mu$ (I.R.), or $0.63 \boldsymbol{\mu}$ (visible).

Key 2 Method to invert the population is avaılable helıum collisions plus relatively long lifetimes of neon states.

Key 3 Resonant cavity. 
neon level pairs. Note that the neon then has to pass through a metastable state in order to return to the ground state. A dominate mechanism for this is a wall collision. This is significant because it requires that the neon migrate to the wall and in essence imposes a pressure-diameter restriction ( $\mathrm{pd}$ - 3-5 Torr-mm for optımum performance).

Now consider substitution of alpha particles, possibly from a neutron-boron reaction, for the electrons involved in the excitation of helium. Some calculations are summarızed in Table IV.

TABLE IV

Helium Metastable Production by Alphas

Pure He $43 \mathrm{eV} /$ Ion pair

$0.1 \% \mathrm{Ar} \quad 30 \mathrm{eV} /$ Ion paır

Penning Effect $\mathrm{He}+\mathrm{Ar} \rightarrow \mathrm{He}+\mathrm{Ar}^{+}+\mathrm{e}^{-}$

$\sim 2$ ion pair $/ 86 \mathrm{eV}$ in $\mathrm{He}=\tilde{U} \sim 3$ pair $/ 3 / 90 \mathrm{eV}$ in $\mathrm{Ar}^{+}$He conclusion

$\sim 1 \mathrm{He} / 90 \mathrm{eV}$

Summary of Calculations by Herwig24

Calculated Upper Laser Density, Atoms/cc

$\Phi_{\text {th }}=10^{13}$ (for 10 Torr $) \quad$ Threshold, $\mathrm{Ne}$

\begin{tabular}{|c|c|c|c|c|}
\hline $3_{\mathrm{He}}$ & $\mathrm{Ne}$ & $6.7 \times 10^{4}$ & .63 & $3.1 \times 10^{8}$ \\
\hline${ }^{10} \mathrm{~B}$ & & $2.1 \times 10^{6}$ & 1.15 & $5.1 \times 10^{7}$ \\
\hline $235_{U}^{D}$ & & $2.7 \times 10^{8}$ & 3.39 & $2 \times 10^{6}$ \\
\hline $210_{\mathrm{Po}}$ & & $3.4 \times 10^{7}$ & & \\
\hline
\end{tabular}

The first question is how many excited states are created in helium per alpha particle? This is a key number, but it is somewhat hard to pin down. We are currently attempting a theoretical calculation, but an experımental observation is indicated here. Consider pure helium. It requires about $43 \mathrm{eV}$ to produce an ion pair. If some argon is added, only $\sim 30 \mathrm{eV}$ are required per ion pair. The difference can be attributed to the Penning effect, i.e., ionization of argon by collision with metastable helium atoms. Thus about $86 \mathrm{eV}$ would produce 2 ion pairs in pure helium whereas $90 \mathrm{eV}$ would produce 3 ion pairs in the Penning mixture. This implies that roughly 1 metastable helium is produced per $90 \mathrm{eV}$ lost by the alpha (This argument was first noted in the report by Herwig.) 
Once this number is known, the threshold equation for lasing can be evaluated, and some typical results are shown in the same table. Also some estimates of the excited state densities are shown assuming that the charged particles are produced by neutron reactions with helıum-3, boron-10 or uranium-235. The values shown assume a neutron flux of $10^{13}$ neutrons $/ \mathrm{cm}^{2}$ sec, a 10 Torr gas pressure, an optımum laser tube diameter and an optimum coating thickness of uranium-235 or boron-10. Consider alphas from boron-10. The values in the "boxes" in the table indicate that a flux of $10^{13}$ should be sufficient to make a helıum-neon laser "go" on the $3.39 \mu$ line (near infrared). Since this assumes an optimum geometry, etc., a higher flux may be required for an actual "as built" laser. Incidentally, the threshold for a laser is roughly inversely proportional to the cube of the wave length, so as one goes from infrared to optical wave lengths, the job becomes more difficult.

These calculations are encouraging because neutron fluxes of over $10^{16}$ during a pulse with the TRIGA reactor can be obtained. This leaves an appropriate safety margin, so the experiment appears feasible. The characteristic width of the reactor pulse is 10-30 milliseconds. This is long relative to lifetımes involved in the lasing cycle, hence the laser would be in a quasıequilibrium state during the pulse.

Figure 17 shows a schematic diagram of an experimental in-core laser in use at Illınos. It is exceedingly simple, in essence a normal laser tube coated with boron. Integral mirror-windows are used to obtain a rugged system which will hold alignment when lowered into the reactor core. The electrical discharge section is used to align the system when the laser is first placed in the reactor. The tube shown is designed to operate on the $3.39 \mu$ line.

There are a number of developmental problems. First, the entire assembly must fit into a fuel element position so the diameter is limited to something under 1-1/4 inches. Secondly the materials of construction, mirrors,etc. must either be radiation resistant or located at a safe distance from the core. Finally, since the reactor core is some 17 feet below water, and since our detector has an active area of about $1 \mathrm{~mm}^{2}$, and since bent tubes and mirrors are needed to prevent gamma and neutron streaming, alıgnment problems are indeed severe. Many hours have been spent at the top of the reactor moving the detector about in vain searching for the infrared laser beam.

While these experiments represent a direct attack on the problem, as noted earlıer we are simultaneously attempting to dissect the problem into smaller studies. I want to mention one such problem to illustrate this. It has to do with the electron slowing-down spectrum in the gas, which is illustrated schematically in Fig. 18. This is a fundamental problem in radiation-produced plasmas, but there is not a complete solution for it in the literature. The problem is similar to the calculation of neutron slowing down spectrum in a thermal reactor. In the present case alpha particles produce electrons in the gas having an average energy of $25 \mathrm{eV}$, and they slow down. The resulting energy spectrum will be considerably different from that produced in $\mathrm{rf}$ or dc discharges. In the latter electric fields accelerate the electrons between collisions. As a result electron "temperatures" are typically 10, 000 degrees or more. In the absence of fields, the plasma produced by alphas may have an 


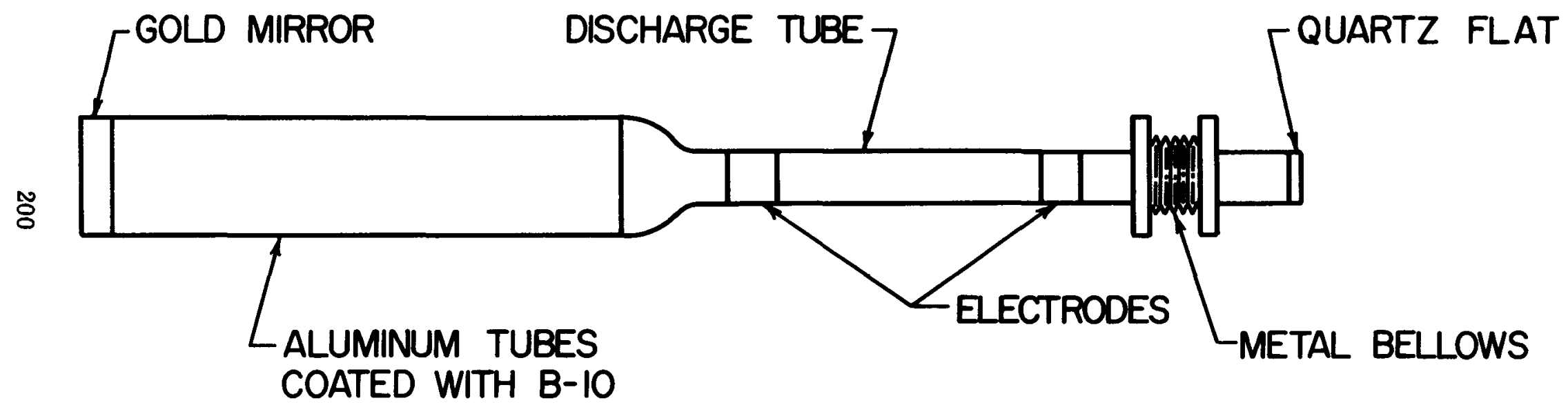

Fig. 17--Sketch of an experimental in-core laser tube (after Guyot, et. al., Ref. 25). 


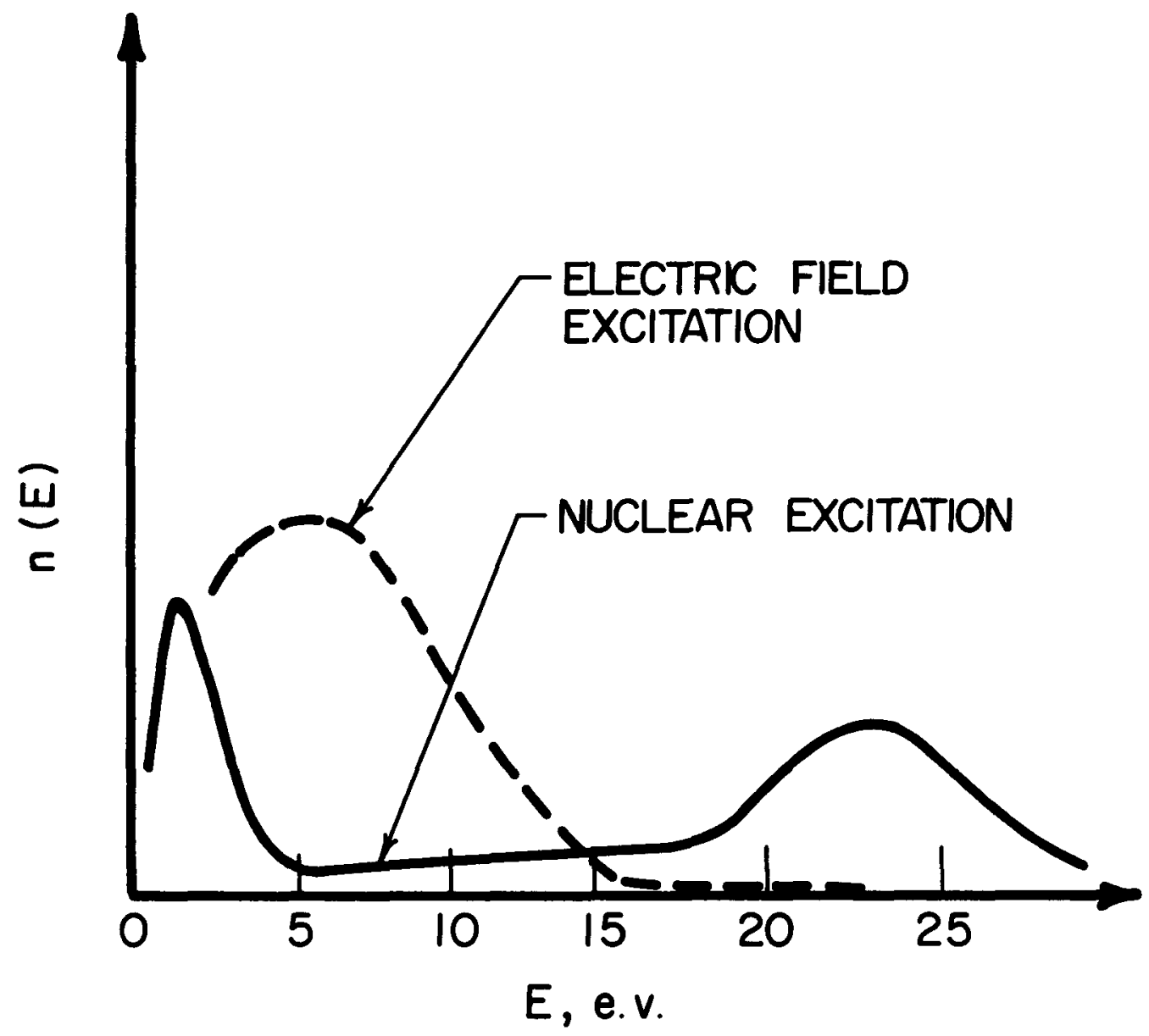

Fig. 18--Postulated electron energy distribution in helium. 
effective temperature closer to the actual gas temperature. 27 The relative rates of electron production and recombination-leakage will in effect determine the detailed thermal spectrum. Of course, the concept of "temperature" applies only to the Maxwellian portion of Fig. 18. As illustrated, the slowing down region must also be accounted for.

The electron energy spectrum is important in the laser calculation. Some of the excitation may be due to direct alpha excitation, but a significant portion will come from the high energy electrons produced by the alphas. The importance of this spectrum can be illustrated by the following argument. The hot electrons in the standard electrical discharge tend to excite neon atoms via collisions from the $1 \mathrm{~S}_{2}$ neon level into the lower lasing levels (recall Fig. 16). This stresses the importance of depopulating the $1 \mathrm{~S}_{2}$ level as quickly as possible by diffusion to the wall, and this is no doubt an important factor in the pressure-diameter restriction noted earlier. Now, if the alpha-excited plasma has a lower electron temperature, the back excitation from the $1 \mathrm{~S}_{2}$ level may not be so important, and it may be possible to relax the pressure-diameter requirement. This would in turn lead to larger power outputs, illustrating one speculative advantage of nuclear radiation pumping. Some other possible advantages, most of which were noted first by Herwig, are listed in Table V.

\section{TABLE V}

Speculative Advantages of Nuclear - Pumping

1. Increased Power via

a. improved coupling vs. rf

b. higher pressure

c. lower electron temperature

2. Improved Control

a. E \& B fields independent of pumping

3. $\frac{\text { Higher Frequencies }}{\text { a. excited ions }}$

4. Compact, Light Weight, Reliable

The University of Illinois has a similar effort involving the lowvoltage arc laser. The experimental laser is illustrated in Fig. 19. It essentially consists of a triode design using plane-parallel electrodes; namely, a heated oxide coated cathode, a plasma stabilizing grid and a movable anode. An electrically heated cathode is used, but the thought is that this could be replaced by heat from a fuel element in an in-core design. The feasibility of a large area cathode such as this along a low-voltage arc, in contrast to the typical small area, high-voltage discharge design, has not been demonstrated experimentally to date. Thus far there are plasma stability problems, but it is hoped that this difficulty can be overcome by some modification of the operating conditions. The initial studies involve helium-neon. This system is understood best so it is preferable for feasibility studies. 

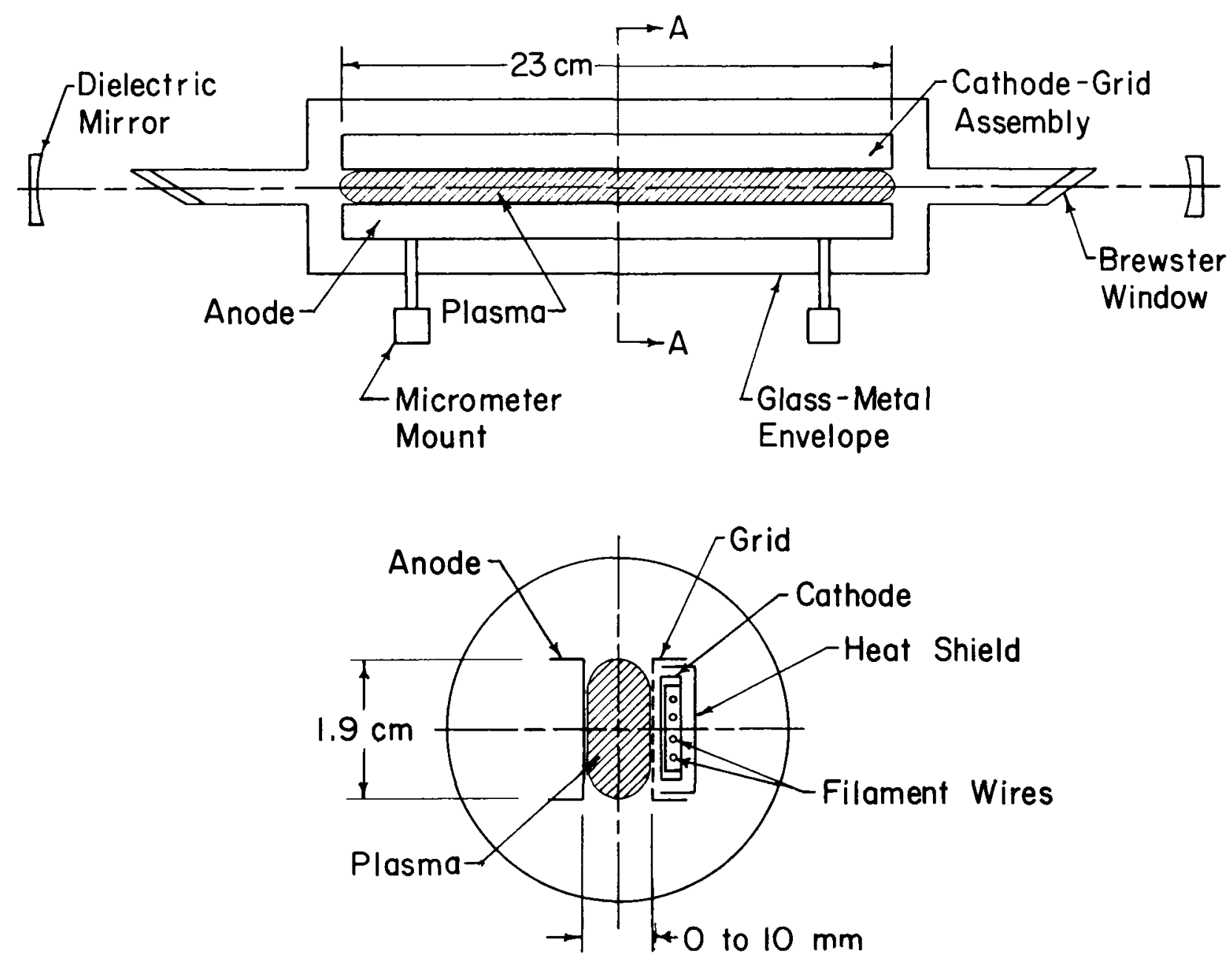

SECTION A-A

Fig. 19--An experimental low-voltage arc laser tube (after Herceg and Miley, Ref. 26). 
The possibility of a low-voltage arc cycle has also been considered by F. M. Johnson. 28 While he did not carry out experiments, he does point out some interesting reasons for considering this approach, and the se are summarized in Table VI.

\title{
TABLE VI
}

\author{
Advantages of Thermionic Laser \\ high efficiency \\ topping cycle concept \\ possibility of alkali-metal lasing \\ also, it may \\ aid understanding of low voltage arc mode (ignited mode) \\ aid understanding of pressure-diameter relations \\ Problems are \\ mechanical - similar to those for thermionic devices \\ designed for in-core or indirect heating \\ sensitivity to impurities in the plasma \\ plasma stability
}

\section{Conclusions}

The things about which I have talked are quite specialized. I have, as have most nuclear engineers, mainly earned my living to date from our "bread and butter" product--the nuclear reactor, and suspect we will continue to do so for a number of years. I do not think we should all immediately jump into a program like the one described here. At the same time, a certain fraction of the total effort should be put into areas such as this, which tend to diversify the field as a whole.

\section{DISCUSSION}

QUESTION: There is currently an unclassified, theoretical paper from Battelle Northwest on pumping the laser. Are you familiar with it?

ANSWER: We have talked some with the Battelle staff about this problem. I am not familiar with the details of the report you mention. (Note added in proof: The report under discussion appears to be BNWL- 452 by B. H. Duane. Rather than dealing with laser pumping it suggests methods for using a laser output to accelerate electrons.)

I would like to reiterate that theoretical work has come fairly easily in this area. A number of people, including ourselves, have shown it works on paper. However, there have been no experimental verifications, and there have been many frustrations. On this connection I should point out that studies using a solid state laser have encountered a radiation "cut-off" effect (see Ref. 9). We ruled this approach out some time ago because of possible radiation damage. This was a fortunate decision. The "cut-off" effect is not 
entirely understood, but essentially, an operating solid-state laser placed in a strong gamma radiation field will be quenched While there may be a way around this problem, it is not going to be easy. Luckily, the same effect would not be expected in a gas laser This has to do with the fact that the solid has a fixed structure whereas gas molecules are of course free to move. The same situation occurs in radiation damage, the gas system has a big advantage.

a difference?

QUESTION Do you mean that just a chemical binding system makes

ANSWER That or the lattice structure The energy levels that are typically involved in a solid-state laser come about because of the bond structure. The effect of nuclear radiation on this structure is different from the effect it has on the atomic levels in the gas.

\section{REFERENCES}

1. G. H. Miley, "Coursework and Experiments in Direct Radiation-ToElectrical Energy Conversion," Trans. Am. Nucl. Soc, 6207 (1963).

2. M. Altman, "Energy Conversion Instıtute Planned," Chem. Eng. Progress, $5812(1962)$.

3. R. J. Martin, F. T. Adler and M. E. Wyman, "Nuclear Engineering, A Program of Graduate Study, "in Conference on Progress in Nuclear Education, Gatlinburg, Tennessee, August 20-22, 1962, USAEC Report $\overline{\text { TID-7638, }}, \overline{\text { pp. } 37-48}$

4. G. H. Miley, "Direct Energy Conversion in Nuclear Engineering,' J. Eng. Edu , 53(6) XXXV (Feb. 1963)

5. P. E Ohmart, "Method and Apparatus for Convertıng Ionic Energy into Electrical Energy," U.S. Patent No. 3, 152, 254, October 6, 1964.

6. P. Thiess (Ed.), "Proc. AEC-ASEE Summer Institute on Direct Energy Conversion," Nucl. Eng. Program, University of Illıno1s, Urbana, 1963

7. E. L. Murphy, "Direct Electricity Generation from Ionized Vapors and Flames, "Tech. Report ONR 1-2-65, Office of Naval Research, American Embassy, London, England, February 1965.

8. M. Steinberg, "Chemonuclear and Radiation Chemical Process Research and Development," Isotopes and Radiation Technology, 4(2) 142 (1966).

9. V. E. Derr, G. T. McNice and P M. Rushworth, "Application of Nuclear Radiation to the Pumping of Lasers" in Radioisotopes for Aerospace Part 2, pp. 309-345, Plenum Press, New York, 1966.

10. F. E. Jamerson, R. H. Abrams, Jr., C. B. Leffert and R. Silver, "Nuclear Generated Plasmas in Noble Gas Thermionic Converters," Adv. Energy Conversion, 3363 (1963). 
11. J. Braun, "Linear Constant-Mach-Number MHD Generator with Nuclear Ionization. A Parameter Study, " J. Nucl. Energy, Part C, 7:525 (1965).

12. G. Safonov, "Direct Conversion of Fission to Electric Energy in Low Temperature Reactors," Report RM-1870, Rand Research Corporation, January 1957.

13. C. J. Heindl, W. F. Krieve and R. V. Meghreblian, "The FissionElectric Cell Reactor Concept," Nucleonics, 21(4):80 (1963).

14. J. N. Anno and S. L. Fawcett, "The Triode Cońcept of Direct Conversion," Battelle Tech. Review, 3-9 (October 1962).

15. E. G. Linder and S. M. Christian, "Use of Radioactive Material for Generation of High Voltage," J.Appl. Phys., 23:1213 (1952).

16. A. M. Plummer and J. N. Anno, "Battelle Studies on the Triode Concept of Direct Energy Conversion" in Proc. AEC-ASEE Summer Institute on Direct Energy Conversion, (P. Thiess, ed.), Nucl. Eng. Program, University of Illinois, Urbana, 1963.

17. W. F. Krieve, "JPL Fission-Electric Cell Experiment," Report JPL Tech. No. 32-981, Jet Propulsion Laboratory, November 1966.

18. W. R. Michelsen and C. A. Low, Jr., "Potentials of Radioisotope Electrostatic Propulsion," Astronautics and Aerospace Eng., pp. 52-57, October 1963.

19. W. R. Corliss and D. G. Harvey, "Radioisotopic Power Generation," Chap. 9, Prentice-Hall, Inc., Englewood Cliffs, N.J., 1964.

20. H. T. Sampson, "Experimental and Theoretical Study of a GammaElectric Cell, "Ph.D. Thesis, Nucl. Eng. Program, University of Illinois, 1967.

21. G. H. Miley, "Direct Energy Conversion Involving Nuclear Radiation," ANS Monograph Series (in preparation).

22. G. H. Miley, "Fission Fragment Transport Effects as Related to FissionElectric-Cell Efficiencies," Nucl. Sci. Eng., 24:332 (1966).

23. J. N. Anno, "Secondary Electron Production from Alpha Particles and Fission Fragments," Ph. D. Thesis, Physics and Astronomy Depts., Ohio State University, 1965.

24. L. O. Herwig, "Summary of Preliminary Studies Concerning Nuclear Pumping of Gas Laser Systems," Research Laboratories, Report No. C-110053-5, United Aircraft Corporation, February 1964.

25. J. C. Guyot, J. T. Verdeyen and G. H. Miley, "Experiments Using Nuclear Radiation to Pump a He-Ne Laser," Fifth Annual Review of Electronics, University of Illinois, November 1967. 
26. J. E. Herceg and G. H. Miley, "A Laser Utilizing a Low-Voltage Arc Discharge in Helium Neon," J.Appl. Physics, 39(4):2147 (1968).

27. A. K. Bhattacharya, "Microwave Investigation of Plasmas Produced in a Nuclear Reactor," Ph. D. Thesis, Nucl. Eng. Program, University of Illinois, Urbana, 1966.

28. F. M. Johnson, "A Laser Excited by Nuclear Heat, "Nucleonics, 22:57 (1959). 